\title{
Spectroscopic Studies of the Corrinoid/Iron-Sulfur Protein from
}

\section{Moorella thermoacetica}

\author{
Troy A. Stich $\dagger$, Javier Seravalli $\ddagger$, Swarnalatha Venkateshrao§, Thomas G. Spiro§, Stephen \\ W. Ragsdale $\ddagger$, and Thomas C. Brunold \\ tDepartment of Chemistry, University of Wisconsin-Madison, Madison, Wisconsin 53706 \\ ‡Department of Biochemistry, University of Nebraska, Lincoln, Nebraska 68588 \\ $\S$ Department of Chemistry, Princeton University, Princeton, New Jersey 08544
}

\section{Abstract}

\begin{abstract}
Methyl transfer reactions are important in a number of biochemical pathways. An important class of methyltransferases uses the cobalt cofactor cobalamin, which receives a methyl group from an appropriate methyl donor protein to form an intermediate organometallic methyl-Co bond that subsequently is cleaved by a methyl acceptor. Control of the axial ligation state of cobalamin influences both the mode (i.e., homolytic vs heterolytic) and the rate of $\mathrm{Co}-\mathrm{C}$ bond cleavage. Here we have studied the axial ligation of a corrinoid iron-sulfur protein (CFeSP) that plays a key role in energy generation and cell carbon synthesis by anaerobic microbes, such as methanogenic archaea and acetogenic bacteria. This protein accepts a methyl group from methyltetrahydrofolate forming $\mathrm{Me}-\mathrm{Co}^{3+} \mathrm{CFeSP}$ that then donates a methyl cation (Me) from Me- $\mathrm{Co}^{3+} \mathrm{CFeSP}$ to a nickel site on acetyl-CoA synthase. To unambiguously establish the binding scheme of the corrinoid cofactor in the CFeSP, we have combined resonance Raman, magnetic circular dichroism, and EPR spectroscopic methods with computational chemistry. Our results clearly demonstrate that the $\mathrm{Me}-$ $\mathrm{Co}^{3+}$ and $\mathrm{Co}^{2+}$ states of the $\mathrm{CFeSP}$ have an axial water ligand like the free $\mathrm{MeCbi}^{+}$and $\mathrm{Co}^{2+} \mathrm{Cbi}^{+}$ cofactors; however, the $\mathrm{Co}-\mathrm{OH}_{2}$ bond length is lengthened by about $0.2 \AA$ for the protein-bound cofactor. Elongation of the $\mathrm{Co}-\mathrm{OH}_{2}$ bond of the CFeSP-bound cofactor is proposed to make the cobalt center more " $\mathrm{Co}^{1+}$-like", a requirement to facilitate heterolytic $\mathrm{Co}-\mathrm{C}$ bond cleavage.
\end{abstract}

\section{Introduction}

A number of anaerobic microbes, including archaea and bacteria, utilize the autotrophic WoodLjungdahl pathway to generate cell carbon and energy from $\mathrm{CO}_{2}$ and $\mathrm{CO} .{ }^{1}$ This pathway consists of two separate branches: the methyl branch, in which five enzymes catalyze the reduction of $\mathrm{CO}_{2}$ to the methyl group of 5-methyltetrahydrofolate $\left(\mathrm{CH}_{3}-\mathrm{H}_{4}\right.$ folate); and the carbonyl branch, wherein the methyl group of $\mathrm{CH}_{3}-\mathrm{H}_{4}$ folate, $\mathrm{CO}_{2}$, and Coenzyme A are converted to acetyl-CoA by the bifunctional $\alpha_{2} \beta_{2}$ tetrameric enzyme termed carbon monoxide dehydrogenase/acetyl-coenzyme A synthase (CODH/ACS). CODH/ACS is equipped with multiple metal cofactors that serve as electron-transfer centers and/or catalytic sites. Each $\beta$ subunit $(\mathrm{CODH})$ houses a unique $[\mathrm{Ni} \mathrm{Fe}]:\left[\mathrm{Fe}_{3} \mathrm{~S}_{4}\right]$ reaction center, ${ }^{2}$ termed the $\mathrm{C}$-cluster, which serves as the site for $\mathrm{CO}_{2}$ reduction. The resulting $\mathrm{CO}$ product is shuttled from $\mathrm{CODH}$ through an intramolecular tunnel to an equally unique $\left[\mathrm{Ni}_{2}-\mathrm{Fe}_{4} \mathrm{~S}_{4}\right]$ center called the A-cluster, which is located in ACS, the $\alpha$-subunit. ${ }^{3-5}$ Here this CO molecule combines with a methyl group donated to the A-cluster by a corrinoid/FeS protein (CFeSP, Scheme 1) to yield a Ni-bound

Supporting Information Difference spectra, Cartesian coordinates for all computational models discussed in the text, plot of $\alpha$-band energy response to lower ligand elongation, and WEPR input files for simulating EPR spectra (PDF). 
acetyl group that is then attacked by the thiolate group of the cosubstrate CoA to generate the acetyl-CoA product. ${ }^{6}$

The $83 \mathrm{kDa}$ heterodimeric CFeSP that delivers the methyl group to the ACS active site (i.e., the A-cluster) (Scheme 1) employs the corrinoid cofactor methyl-Co ${ }^{3+}-5$ -

methoxybenzimidazolylcobamide (Factor $\mathrm{III}_{\mathrm{m}}$, Figure 1$)^{7,8}$ that is bound to the $35 \mathrm{kDa}$ subunit of this enzyme. ${ }^{9}$ The structure of Factor $\mathrm{III}_{\mathrm{m}}$ is nearly identical to that of the methylcobalamin (MeCbl) cofactor employed by methionine synthase (MetH) $;{ }^{10}$ however, in contrast to the 5,6dimethylbenzimidazole/nucleotide loop assembly found in $\mathrm{MeCbl}$, Factor $\mathrm{III}_{\mathrm{m}}$ employs a 5methoxybenzimidazolyl (MBI) nitrogen base that is tethered to the corrin ring at $\mathrm{C}^{17}$ through a propionamide linkage. ${ }^{11}$ When extracted from the CFeSP, the isolated cofactor is coordinated in the lower axial position by MBI. Interestingly, though, electron paramagnetic resonance (EPR) and electronic absorption (Abs) studies of CFeSP revealed that this base is no longer ligated to the central Co ion when the cofactor is bound to the protein. ${ }^{12}$

Methylation of the bound corrinoid to yield $\mathrm{Me}-\mathrm{Co}^{3+} \mathrm{CFeSP}$ is catalyzed by a methyltransferase (MeTr, Scheme 1), where the methyl group derives from $\mathrm{CH}_{3}-\mathrm{H}_{4}$ folate originating from the methyl branch of the Wood-Ljungdahl pathway. During catalytic turnover, the $\mathrm{Me}-\mathrm{Co}^{3+} \mathrm{CFeSP}$ formally transfers a methyl cation to the ACS A-cluster through heterolytic cleavage of the $\mathrm{Co}-\mathrm{C}$ bond, resulting in the formation of a transient $\mathrm{Co}^{1+}$ corrinoid species that is subsequently remethylated by MeTr. However, the $\mathrm{Co}^{2+/ 1+}$ reduction potential of the CFeSP-bound corrinoid is very negative, $E^{\circ}=-504 \mathrm{mV},{ }^{13}$ leading to oxidation of the $\mathrm{Co}^{1+}$ intermediate to the catalytically inactive $\mathrm{Co}^{2+}$ state about 1 out of every 100 turnovers.

14 Intriguingly, metal analysis as well as Mössbauer and EPR spectroscopic studies revealed that the $48 \mathrm{kDa}$ subunit of CFeSP contains a $\left[\mathrm{Fe}_{4} \mathrm{~S}_{4}\right]$ cluster that functions to reduce the $\mathrm{Co}^{2+}$ form of the corrinoid back to the active $\mathrm{Co}^{1+}$ state. ${ }^{12,14,15}$ The $\left[\mathrm{Fe}_{4} \mathrm{~S}_{4}\right]^{2+/ 1+}$ reduction potential of this cluster is $E^{\circ}=-523 \mathrm{mV}$, which is nearly isopotential with the $\mathrm{Co}^{2+/ 1+}$ couple of the corrinoid. Removal of Factor $\mathrm{III}_{\mathrm{m}}$ from the CFeSP by treatment with urea has no noticeable effect on the Mössbauer and EPR properties of the $\left[\mathrm{Fe}_{4} \mathrm{~S}_{4}\right]$ cluster and raises the $\left[\mathrm{Fe}_{4} \mathrm{~S}_{4}\right]^{2+/ 1+}$ reduction potential by a mere $\sim 6 \mathrm{mV}$. Likewise, the addition of mersalyl acid, which disrupts the $\left[\mathrm{Fe}_{4} \mathrm{~S}_{4}\right]$ cluster without perturbing the EPR spectrum of the CFeSP-bound $\mathrm{Co}^{2+}$ corrinoid cofactor, has negligible effects on the midpoint potential of the $\mathrm{Co}^{2+/ 1+}$ couple, demonstrating that the two metal cofactors are electronically uncoupled. ${ }^{13}$

While the functional roles of both metal cofactors in CFeSP are well understood, fundamental questions concerning the exact nature of the coordination environment of the corrinoid remain unanswered. Results from previous X-ray absorption fine structure (EXAFS) studies of both $\mathrm{Me}-\mathrm{Co}^{3+} \mathrm{CFeSP}$ and $\mathrm{Co}^{2+} \mathrm{CFeSP}$ suggested that, in each case, the enzyme-bound corrinoid lacks a lower axial ligand, thus adopting an unprecedented five-coordinate and four-coordinate Co-coordination environment, respectively. ${ }^{16,17}$

However, this hypothesis appears to be inconsistent with the published EPR spectrum of $\mathrm{Co}^{2+} \mathrm{CFeSP},{ }^{12}$ which is interpreted as indicating the presence of an oxygen-based ligand (vide infra) in one of the axial positions of the cobalt center. Nonetheless, a subsequent detailed analysis of the pre-edge features in the X-ray absorption (XAS) spectrum of the $\mathrm{Co}^{2+} \mathrm{CFeSP}$ continued to suggest that the $\mathrm{Co}^{2+}$ corrinoid cofactor exists in an unprecedented four-coordinate square-planar geometry. ${ }^{16,18}$

Numerous thermodynamic studies of alkylated corrinoid model complexes have shown that the nature of the lower ligand has a considerable influence on both the mode (i.e., homolytic vs heterolytic) and the rate of $\mathrm{Co}-\mathrm{C}$ bond cleavage. ${ }^{19-23}$ Consequently, the lower axial ligand is expected to play a key role in controlling both the reaction of $\mathrm{Co}^{1+} \mathrm{CFeSP}$ with $\mathrm{CH}_{3}-$ $\mathrm{H}_{4}$ folate and the transfer of the methyl cation from $\mathrm{Me}-\mathrm{Co}^{3+} \mathrm{CFeSP}$ to the ACS A-cluster, and 
it is therefore of considerable interest to unambiguously establish the binding scheme of the corrinoid cofactor in CFeSP. To this end, we have employed our recently developed combined spectroscopic and computational methodology $y^{24-27}$ to probe the electronic structures, and thus indirectly the axial ligand interactions, of the methylated and $\mathrm{Co}^{2+}$-containing forms of Factor $\mathrm{III}_{\mathrm{m}}$ in the CFeSP active site.

\section{Experimental}

\section{Purification of the CFeSP and Sample Preparation}

The CFeSP from Moorella thermoacetica was purified to $>95 \%$ homogeneity inside an anaerobic chamber (Vacuum Atmospheres, Hawthorne, CA), at an oxygen level of less than $2 \mathrm{ppm}$ at $18{ }^{\circ} \mathrm{C}$, according to a previously published procedure. ${ }^{12} \mathrm{Me}-\mathrm{Co}^{3+} \mathrm{CFeSP}$ was prepared by reducing as-isolated CFeSP with 5 equiv of titanium citrate per mol of enzyme and subsequently adding $2-3$ equiv of methyl iodide. After incubation at $55^{\circ} \mathrm{C}$ for $\sim 10 \mathrm{~min}$, the samples were allowed to cool to room temperature. Conversion to the methylated product was confirmed by electronic absorption (Abs) spectroscopy. The extent of methylation was quantified by parallel radiolabeling studies using ${ }^{14} \mathrm{C}$-labeled methyl iodide, which showed the incorporation of 1.0 methyl groups/heterodimer. All resulting protein solutions were concentrated for further spectroscopic studies using an Amicon filter equipped with a YM30 membrane.

\section{Spectroscopy}

Samples used for Abs, circular dichroism (CD), and magnetic CD (MCD) experiments were prepared by mixing suitably concentrated protein solutions (in $0.1 \mathrm{M} \mathrm{TRIS} / \mathrm{HCl}, \mathrm{pH} 7.60$ ) with the glassing agent glycerol $(45 \% \mathrm{v} / \mathrm{v})$ and injecting the resulting mixtures into MCD cells that were then immediately frozen in liquid nitrogen. All $4.5 \mathrm{~K}$ Abs spectra obtained in this study were consistent with previously published room-temperature data, indicating that the addition of glycerol and subsequent freezing had negligible effects on the CFeSP-bound corrinoid cofactor. Sample concentrations ranged from 0.5 to $1.0 \mathrm{mM} \mathrm{CFeSP}$ and were determined spectrophotometrically at $300 \mathrm{~K}$ on the basis of published molar extinction coefficients (i.e., $\varepsilon_{470 \mathrm{~nm}}=13.2 \mathrm{mM}^{-1} \mathrm{~cm}^{-1}$ for the $\mathrm{Co}^{2+} \mathrm{CFeSP}$ and $\varepsilon_{450 \mathrm{~nm}}=12.5 \mathrm{mM}^{-1} \mathrm{~cm}^{-1}$ for Me-Co CFeSP). ${ }^{12}$ Adenosylcobinamide ( $\mathrm{AdoCbi}^{+}$) was prepared enzymatically as described previously. ${ }^{28}$ Low-temperature Abs, CD, and MCD spectra were recorded using a JACSO J-715 spectropolarimeter in conjunction with an Oxford Instruments SM-4000 8T magnetocryostat. The MCD spectra reported herein were obtained by subtracting the $-7 \mathrm{~T}$ spectrum from the $+7 \mathrm{~T}$ spectrum to eliminate the natural $\mathrm{CD}$ contributions. Resonance Raman (rR) samples of $\mathrm{H}_{3} \mathrm{C}-,{ }^{2} \mathrm{H}_{3} \mathrm{C}$-, and $\mathrm{H}_{3}{ }^{13} \mathrm{C}$-bound $\mathrm{Me}-\mathrm{Co}^{3+} \mathrm{CFeSP}$ were prepared as described above, using the correspondingly labeled methyl iodides. Aliquots of $10-15 \mu \mathrm{L}$ of the resulting $2-3 \mathrm{mM} \mathrm{Me}-\mathrm{Co}^{3+} \mathrm{CFeSP}$ solution were loaded under anaerobic and reduced light conditions into sample cells consisting of $2 \mathrm{~mm}$ holes drilled into a $3 \mathrm{~mm}$ thick copper plate. The copper plate was attached to a coldfinger and inserted into a liquid nitrogen dewar that was then placed under vacuum to degas the sample and prevent frost formation. Samples of free base-off $\mathrm{MeCbl}$ were prepared by dissolving $\mathrm{MeCbl}$ (purchased from Sigma) in $0.1 \mathrm{M} \mathrm{HCl}$, and the resulting solutions were loaded onto the coldfinger as described above for the enzyme sample. All rR spectra were accumulated upon excitation at $441.6 \mathrm{~nm}$ using a Liconix 4200 series He-Cd laser (model 4240NB) with $\sim 16-18 \mathrm{~mW}$ laser power at the sample that was cooled to $77 \mathrm{~K}$ to inhibit laser induced $\mathrm{Co}-\mathrm{C}$ bond photolysis. The scattered light was collected in an $\sim 135^{\circ}$ backscattering geometry and focused onto the slit of a Spex 1877 triple monochromator equipped with a 2400 groves $/ \mathrm{mm}$ grating. A liquid nitrogen cooled charge coupled device (Spec-10 system, Princeton Instruments) with $1340 \times 400$ pixels was used as the multichannel detector. Raman shifts were calibrated using $N, N$-dimethylformamide as a standard loaded into an adjacent sample cell. 
EPR spectra were recorded at $100 \mathrm{~K}$ using a Bruker EMX spectrometer (Billerica, MA) equipped with an X-band High Sensitivity resonator, an HP5352B frequency counter (HewlettPackard, Palo Alto, CA), and an ESR 900 continuous flow cryostat (Oxford, Billerica, MA). All other pertinent details for EPR data acquisition are provided in the caption of Figure 3. $\mathrm{Co}^{2+} \mathrm{CFeSP}$ EPR samples were prepared by concentrating $\sim 120 \mathrm{nmol}$ of protein, resuspending the pellet in $20 \mu \mathrm{L}$ of $1 \mathrm{M}$ potassium phosphate buffer $\mathrm{pH}=7.8$, and slowly adding $180 \mu \mathrm{L}$ of either $\mathrm{H}_{2} \mathrm{O}$ or $\mathrm{H}_{2}{ }^{17} \mathrm{O}$. Total spin concentrations as determined by double integration of the $100 \mathrm{~K}$ spectra were found to be $0.40 \mathrm{mM}$ and $0.44 \mathrm{mM}$ for the $\mathrm{H}_{2} \mathrm{O}$ and $\mathrm{H}_{2}{ }^{17} \mathrm{O}$ samples, respectively. The final level of $\mathrm{H}_{2}{ }^{17} \mathrm{O}$ enrichment was estimated to be $60 \%$ based on the dilution of water into the sample mixture. EPR data were simulated using the WEPR program written by Dr. Frank Neese. The parameter sets employed for these EPR simulations are given in the Supporting Information.

\section{Computational Methods}

The combined quantum mechanical/molecular mechanical (QM/MM) approach ${ }^{29}$ was employed to generate corrinoid models that have been shown to accurately predict the corresponding geometric and electronic structures. ${ }^{30}$ As no crystal structures have yet been reported for $\mathrm{Me}-\mathrm{Co}^{3+} \mathrm{CFeSP}$ and free base-off $\mathrm{MeCbl}$ (as well as the closely related derivative methylcobinamide, $\mathrm{MeCbi}^{+}$), an initial model of the enzyme-bound cofactor (Figure 1) was constructed on the basis of the high-resolution $(0.8 \AA)$ crystal structure data available for baseon MeCbl. ${ }^{31}$ The nucleotide loop was cleaved at the phosphoester bond proximal to $\mathrm{C}^{17}$, and the remaining distal loop fragment was deleted. A water molecule was substituted for the DMB base in the lower axial position, and the geometry of the entire model was optimized using the QM/MM method ${ }^{32,33}$ as implemented in the Amsterdam Density Functional (ADF) 2004.01 suite of programs. ${ }^{34-36}$ Only those atoms that were expected to have a significant electronic influence on the geometry of this $\mathrm{MeCbi}^{+}$model were treated at the QM level; namely, the cobalt center, both axial ligands $\left(\mathrm{H}_{2} \mathrm{O}\right.$ and $\left.\mathrm{CH}_{3}\right)$, and all atoms that comprise the corrin macrocycle. The computational treatment of this QM region employed the Vosko-WilkNusair local density approximation (VWN-LDA) ${ }^{37}$ and the gradient corrections of Becke ${ }^{38}$ and Perdew ${ }^{39}$ for exchange and correlation, respectively, along with the ADF IV basis set (triple $\zeta$ with polarization on all heavy atoms). Alternatively, the atoms of the corrin ring substituents that have merely steric/electrostatic influences on the cofactor geometry were treated at the MM level using the Amber 95 force field $^{40}$ and were coupled to the QM region using the multipole derived charge analysis model as implemented in $\mathrm{ADF} .{ }^{41} \mathrm{QM} / \mathrm{MM}$ geometries were updated using the BFGS Hessian scheme in optimizations carried out with an integration constant of 4.0 on a cluster of Pentium Xeon processors (ACE Computers).

Using this optimized model as a starting geometry, the effects of lower ligand distortions on the geometric structure of $\mathrm{MeCbi}^{+}$were examined by varying the $\mathrm{Co}-\mathrm{O}$ bond length in fixed increments of $0.1 \AA$ between 1.800 and $3.000 \AA$ and reoptimizing the positions of all remaining atoms using the $\mathrm{QM} / \mathrm{MM}$ method described above. The effects of these distortions on the predicted ground and excited-state electronic properties were investigated by density functional theory (DFT) and time-dependent DFT (TD-DFT) calculations, which were carried out on a desktop PC using the ORCA 2.2 software package developed by Dr. Frank Neese (MPI Mülheim, Germany). ${ }^{42}$ As the QM/MM optimized models of $\mathrm{MeCbi}^{+}$were too large for computations based entirely on DFT, the corresponding QM region of each model was excised and used as-is for all subsequent calculations. Ground-state DFT calculations employed Becke's three-parameter hybrid functional for exchange ${ }^{43,44}$ combined with the Lee-YangParr correlation functional ${ }^{45}$ (B3LYP/G) using the default $20 \%$ Hartree-Fock exchange. All atoms were treated with the $\mathrm{SV}(\mathrm{P})$ (Ahlrichs polarized split valence) basis ${ }^{46}$ in conjunction with the SV/C auxiliary basis with the exception of the Co center for which the TZVP triple$\zeta$ basis was used. ${ }^{47}$ Electronic transition energies and intensities for all models were computed 
by the TD-DFT method ${ }^{48-50}$ within the Tamm-Dancoff approximation ${ }^{51,52}$ as implemented in ORCA 2.2, using the same functional and basis sets described above for the ground-state calculations. In each case, 60 excited states were computed by including all one-electron excitations between molecular orbitals within \pm 3 hartrees of zero energy. To increase computational efficiency, the resolution of the identity approximation was employed in calculating the Coulomb term. ${ }^{53}$ The TD-DFT results were then used to simulate Abs spectra assuming that each electronic transition gives rise to a Gaussian-shaped band with a full width at half-maximum of $v_{1 / 2}=1250 \mathrm{~cm}^{-1}$. Under this assumption, the molar extinction coefficient $\varepsilon_{\max }\left(\mathrm{M}^{-1} \mathrm{~cm}^{-1}\right)$ is related to the TD-DFT predicted oscillator strength $f$ according to the formula $f=4.61 \times 10^{-9} \varepsilon_{\max } v_{1 / 2}{ }^{54}$ All spectra were red-shifted by $3000 \mathrm{~cm}^{-1}$ to compensate for the fact that transition energies for $\mathrm{Co}^{3+}$-corrinoids and similar systems are consistently overestimated by the B3LYP TD-DFT method. ${ }^{24-27,49,53,55-57}$

\section{Results and Analysis}

\section{Spectroscopic Studies. (i) Abs, CD, and MCD Spectra of $\mathrm{Co}^{2+} \mathrm{CFeSP}$}

The $4.5 \mathrm{~K}$ electronic absorption (Abs) spectrum of as-isolated $\mathrm{CFeSP}\left(\mathrm{Co}^{2+} \mathrm{CFeSP}\right)$ is presented in Figure 2 along with that of free $\mathrm{Co}^{2+}$ cobinamide $\left(\mathrm{Co}^{2+} \mathrm{Cbi}^{+}\right)$, a cobalamin derivative that lacks the nucleotide base and consequently coordinates a water molecule in the lower axial position. ${ }^{25,58,59}$ Both spectra exhibit a broad feature in the visible region with an absorption maximum at $470 \mathrm{~nm}\left(21,200 \mathrm{~cm}^{-1}\right)$; however, the $\mathrm{Co}^{2+} \mathrm{CFeSP}$ spectrum possesses additional intensity near $420 \mathrm{~nm}\left(23,800 \mathrm{~cm}^{-1}\right)$ that we attribute to $\mathrm{S} \rightarrow \mathrm{Fe}^{3+}$ charge-transfer transitions from the oxidized $\left[\mathrm{Fe}_{4} \mathrm{~S}_{4}\right]$ cluster present in this sample. In support of this assignment, taking the difference of the two Abs spectra presented in Figure 2 yields a trace (Figure S1) that is very similar to the Abs spectrum reported for the $\left[\mathrm{Fe}_{4} \mathrm{~S}_{4}\right]^{2+}$ component of CFeSP lacking the corrinoid cofactor. ${ }^{12}$ The Abs feature at $470 \mathrm{~nm}$, termed the $\alpha$-band, has been shown to arise from the lowest-energy corrin-based $\pi \rightarrow \pi^{*}$ ( $\operatorname{cor} \pi \rightarrow \pi^{*}$ ) transition. Past spectroscopic and computational studies have shown that the energy of this band is quite sensitive to the nature of the axial ligand found in $\mathrm{Co}^{2+}$ corrinoids. ${ }^{25}$ Hence the fact that the $\alpha$-band in the spectra of the CFeSP-bound corrinoid and free $\mathrm{Co}^{2+} \mathrm{Cbi}^{+}$appears at precisely the same energy precludes any significant differences in axial ligand bonding interactions between the free and enzyme-bound cofactors.

The 4.5 K CD spectrum of $\mathrm{Co}^{2+} \mathrm{CFeSP}$ contains features at 13,750, 15,900, 22,450, and 23,350 $\mathrm{cm}^{-1}$ that have no counterparts in the free $\mathrm{Co}^{2+} \mathrm{Cbi}^{+}$spectrum, suggesting that they arise from the oxidized $\left[\mathrm{Fe}_{4} \mathrm{~S}_{4}\right]$ cluster. Intriguingly, the positions and relative intensities of these $\mathrm{CD}$ bands do not follow the spectral pattern typically observed for the $\left[\mathrm{Fe}_{4} \mathrm{~S}_{4}\right]^{2+}$ state of ferredoxintype or high-potential [FeS] clusters. ${ }^{60}$ This difference perhaps reflects the necessity of the $\left[\mathrm{Fe}_{4} \mathrm{~S}_{4}\right]$ cluster of CFeSP to possess a somewhat unique electronic structure as judged on the basis of the unusually low midpoint potential of $-523 \mathrm{mV}$ versus SHE. ${ }^{13}$

While both the Abs and CD spectroscopic data of the $\mathrm{Co}^{2+} \mathrm{CFeSP}$ presented above contain significant contributions from the diamagnetic $\left[\mathrm{Fe}_{4} \mathrm{~S}_{4}\right]^{2+}$ cluster, the corresponding $4.5 \mathrm{~K} 7 \mathrm{~T}$ MCD spectrum should be dominated entirely by the corrinoid features due to the dramatic enhancement of MCD $C$-terms arising from paramagnetic species at low temperatures. Indeed, all features in the $\mathrm{Co}^{2+} \mathrm{CFeSP} \mathrm{MCD}$ spectrum (Figure 2) were found to decrease in intensity with increasing temperature as predicted for an $S=1 / 2$ species. Inspection of Figure 2 reveals that, although the $\mathrm{Co}^{2+} \mathrm{CFeSP}$ MCD spectrum is quite similar to the free $\mathrm{Co}^{2+} \mathrm{Cbi}^{+}$spectrum, some notable differences occur in the low energy region $\left(<20,000 \mathrm{~cm}^{-1}\right)$ where $\mathrm{Co}^{2+} \mathrm{d} \rightarrow \mathrm{d}$ transitions produce the dominant spectral contributions. In particular, two broad temperaturedependent features centered at 13,000 and $14,700 \mathrm{~cm}^{-1}$ are exclusive to the spectrum of the as-isolated enzyme. However, $\mathrm{MCD}$ data of the reduced $\left[\mathrm{Fe}_{4} \mathrm{~S}_{4}\right]$ ferredoxin from Clostridium pasteurianum exhibit a strikingly similar pattern of features at 13,500 and $15,000 \mathrm{~cm}^{-1}$ (as 
well as $\left.19,000 \mathrm{~cm}^{-1}\right),{ }^{61}$ suggesting that all the major differences between the two MCD spectra shown in Figure 2 are due to the presence of a small fraction of $\left[\mathrm{Fe}_{4} \mathrm{~S}_{4}\right]^{1+}$ cluster in the protein sample. Nonetheless, a quantitative spectral analysis of the $\mathrm{Co}^{2+} \mathrm{CFeSP}$ MCD data revealed that minor shifts do occur for some of the $\mathrm{Co}^{2+} \mathrm{d} \rightarrow \mathrm{d}$ transitions (see Table 1) from their positions determined for free $\mathrm{Co}^{2+} \mathrm{Cbi}^{+}$by a simultaneous Gaussian deconvolution of the $\mathrm{Abs}$, CD, and MCD spectra. ${ }^{25}$ This perturbation of the relative energies of the $\mathrm{Co}^{2+} \mathrm{d}$-based MOs is intriguing but not necessarily unexpected, as the $\mathrm{Co}^{2+/ 1+}$ reduction potential of the free $\mathrm{Co}^{2+} \mathrm{Cbi}^{+}$is $\sim 14 \mathrm{mV}$ more positive than that of the CFeSP-bound corrinoid. In fact, the relatively small shifts observed for some $\mathrm{Co}^{2+} \mathrm{d} \rightarrow \mathrm{d}$ transitions (e.g., $150 \mathrm{~cm}^{-1}$ for band 1 , Table 1) in response to cofactor binding to the enzyme active site likely reflects a slight destabilization of the $\mathrm{Co}^{2+} \mathrm{d}_{z 2}$-based redox active orbital and thus a minor depression of the $\mathrm{Co}^{2+/ 1+}$ reduction potential. Ultimately, however, the close resemblance of the two data sets in Figure 2 precludes any significant differences between the $\mathrm{Co}^{2+}$ ligand environments in $\mathrm{Co}^{2+} \mathrm{Cbi}^{+}$and $\mathrm{Co}^{2+} \mathrm{CFeSP}$.

\section{EPR Studies of $\mathrm{Co}^{2+} \mathrm{CFeSP}$}

The X-band EPR spectrum of $\mathrm{Co}^{2+} \mathrm{CFeSP}$ in natural abundance $\mathrm{H}_{2} \mathrm{O}$ (Figure 3, top) is essentially identical to that previously reported by Ragsdale and co-workers. ${ }^{12}$ The pattern of eight negative resonances centered at $g_{\|}=2.0$ and split by $144 \mathrm{G}$ results from the unpaired electron localized in the Co $3 \mathrm{~d}_{z 2}$-based orbital interacting with the spin of the ${ }^{59} \mathrm{Co}$ nucleus $(I=7 / 2) .{ }^{62,63}$ The lack of any additional fine structure due to coupling from a ${ }^{14} \mathrm{~N}$ nucleus $(I$ $=1$ ) confirms that the CFeSP-bound cofactor exists in the base-off conformation where the MBI ligand is dissociated, thus opening a potential coordination site for either a solvent molecule or a CFeSP-active site residue. Parallel experiments using $\mathrm{Co}^{2+} \mathrm{CFeSP}$ resuspended in $\mathrm{H}_{2}{ }^{17} \mathrm{O}$ enriched buffer yielded an EPR spectrum suffering from significant broadening and an $\sim 60 \%$ decrease in intensity throughout the $g_{\|}$region (2800-4000 G) compared to the spectrum obtained in $\mathrm{H}_{2}{ }^{16} \mathrm{O}$ (Figure 3 ). This dramatic loss of intensity correlates almost exactly to the level of $\mathrm{H}_{2}{ }^{17} \mathrm{O}$ enrichment (60\%, see Experimental Section) and, thus, must be attributed to spectral broadening induced by the strong superhyperfine coupling of the electron spin to the ${ }^{17} \mathrm{O}(I=5 / 2)$ nucleus of a water molecule bound to the $\mathrm{Co}^{2+}$ center. Although simulation of the natural abundance $\mathrm{Co}^{2+} \mathrm{CFeSP}$ spectrum (Figure 3, top) required slightly larger ${ }^{59} \mathrm{Co}$ hyperfine values $A_{\mathrm{i}}\left({ }^{59} \mathrm{Co}\right)$ compared to those reported for free $\mathrm{Co}^{2+} \mathrm{Cbi}^{+}, 27$ overall, the EPR parameters for the free and enzyme-bound cofactors are quite similar (Table 2). The spectrum obtained in $\mathrm{H}_{2}{ }^{17} \mathrm{O}$ was fit assuming a $40 \%$ contribution from the $\mathrm{H}_{2}{ }^{16} \mathrm{O}$ spectrum described above. The remaining spectral intensity was simulated using ${ }^{17} \mathrm{O}$ hyperfine tensor elements $A_{\mathrm{i}}\left({ }^{17} \mathrm{O}\right)$ set to values calculated by the coupled-perturbed SCF DFT method for a $\mathrm{Co}^{2+} \mathrm{Cbi}^{+}$ model described in our earlier work ${ }^{25}$ (see Supporting Information for computational details). This treatment resulted in an excellent reproduction of the different intensity distribution within the labeled and unlabeled spectra and an accurate prediction of the fine structure caused by superhyperfine coupling to the ${ }^{17} \mathrm{O}$ nucleus (Figure 3 ).

\section{Abs, CD, and MCD Spectra of Me-Co ${ }^{3+}$ CFeSP}

Similar to the case of $\mathrm{Co}^{2+} \mathrm{CFeSP}$, the electronic Abs spectrum of the CFeSP containing the methylated corrinoid cofactor $\left(\mathrm{Me}-\mathrm{Co}^{3+} \mathrm{CFeSP}\right)$ is dominated by a broad feature in the visible region that, in this case, is reminiscent of the $\alpha$-band in the Abs spectrum of free adenosylcobinamide (AdoCbi ${ }^{+}$, Figure 4). ${ }^{24}$ The appearance of this band at $450 \mathrm{~nm}(22,200$ $\mathrm{cm}^{-1}$ ) in the protein spectrum eliminates the possibility that the methoxybenzimidazolyl (MBI) moiety of Factor III $_{\mathrm{m}}$ directly coordinates to the cobalt center, as the $\alpha$-bands of alkylated corrinoids with $\mathrm{N}$-donor ligands in the lower axial position consistently peak between 535 and $515 \mathrm{~nm}\left(18,700-19,500 \mathrm{~cm}^{-1}\right)$. While this result suggests that the MBI ligand is displaced by a water molecule in the enzyme-bound cofactor, the $\alpha$-band in the $\mathrm{Me}-\mathrm{Co}^{3+} \mathrm{CFeSP} \mathrm{Abs}$ spectrum is blue-shifted by $8 \mathrm{~nm}\left(390 \mathrm{~cm}^{-1}\right)$ relative to that of free $\mathrm{AdoCbi}^{+}$(Figure 4), 
signaling, perhaps, a previously unknown mode of cofactor binding. The origin of this blue shift is addressed below in the Computational Studies section. The remaining spectral differences between the Abs spectra of $\mathrm{Me}-\mathrm{Co}^{3+} \mathrm{CFeSP}$ and $\mathrm{AdoCbi}^{+}$can be ascribed to contributions from the oxidized $\left[\mathrm{Fe}_{4} \mathrm{~S}_{4}\right]^{2+}$ cluster to the former, as the single intense feature in the difference spectrum is a broad band centered at $420 \mathrm{~nm}$ (Figure S2).

The CD spectra of $\mathrm{Me}-\mathrm{Co}^{3+} \mathrm{CFeSP}$ and $\mathrm{AdoCbi}^{+}$(Figure 4, middle) are quite similar in that both exhibit a prominent positively signed feature at $330 \mathrm{~nm}\left(30,300 \mathrm{~cm}^{-1}\right)$. Removing the contributions from the methylated corrinoid via the same subtraction procedure employed for the Abs spectra yields a CD spectrum with features at 13,500, 15,800, 17,800, and 23,400 $\mathrm{cm}^{-1}$, which line up almost exactly with the series of peaks observed in the difference CD spectrum between $\mathrm{Co}^{2+} \mathrm{CFeSP}$ and $\mathrm{Co}^{2+} \mathrm{Cbi}^{+}$described above. This high degree of similarity provides further support for our assumption that these four features arise from the $\left[\mathrm{Fe}_{4} \mathrm{~S}_{4}\right]^{2+}$ cluster. The fact that the positions of all four features are identical (within experimental error) in the two difference spectra indicates that the electronic properties of the $\left[\mathrm{Fe}_{4} \mathrm{~S}_{4}\right]^{2+}$ cluster do not depend on the Co oxidation state, consistent with previous potentiometric studies. ${ }^{13}$

As both the methylated Factor $\mathrm{III}_{\mathrm{m}}$ and the oxidized $\left[\mathrm{Fe}_{4} \mathrm{~S}_{4}\right]^{2+}$ cluster are diamagnetic, the $\mathrm{MCD}$ spectral intensity of $\mathrm{Me}-\mathrm{Co}^{3+} \mathrm{CFeSP}$ should be temperature-independent. However, the corresponding MCD spectrum obtained at $7 \mathrm{~T}$ actually exhibited temperature-dependent features attributed to a minor fraction of reduced $\mathrm{Co}^{2+} \mathrm{CFeSP}$ (cf. Figures $\mathrm{S} 4$ and 2). Yet, by elevating the temperature to $100 \mathrm{~K}$, the contributions from this paramagnetic impurity could be eliminated, yielding an MCD spectrum similar to that of free $\mathrm{AdoCbi}^{+}$with respect to the relative intensities and energies of the dominant features (Figure 4, bottom). Note that the contributions from the $\left[\mathrm{Fe}_{4} \mathrm{~S}_{4}\right]^{2+}$ cluster to the MCD spectrum of Me-Co ${ }^{3+} \mathrm{CFeSP}$ should be insignificant, as they are expected to be $\sim 50$-fold less intense than MCD features associated with the $\mathrm{Co}^{3+}$ form of the corrinoid. 61

\section{Resonance Raman Data of Me-Co ${ }^{3+} \mathrm{CFeSP}$}

The visible region of the Abs spectrum of $\mathrm{Me}-\mathrm{Co}^{3+} \mathrm{CFeSP}$ has contributions from both the corrinoid and the oxidized $\left[\mathrm{Fe}_{4} \mathrm{~S}_{4}\right]^{2+}$ cluster (vide supra); therefore, laser excitation near the center of this Abs envelope is expected to give rise to resonance Raman enhancement of vibrational features from both cofactors. In Figure 5, the low-frequency region of the resonance Raman (rR) spectra obtained with $441.6 \mathrm{~nm}$ laser excitation of Me- $\mathrm{Co}^{3+} \mathrm{CFeSP}$ samples are compared to that of base-off $\mathrm{MeCbl}(\mathrm{pH}=1)$. Isotopic labeling of the axial methyl group of free base-off $\mathrm{MeCbl}$ has previously been used to identify the $\mathrm{Co}-\mathrm{C}$ stretching $\left(v_{\mathrm{Co}-\mathrm{C}}\right)$ mode as the peak appearing at $501 \mathrm{~cm}^{-1}$ (Figure 5A). ${ }^{64}$ To determine if $v_{\mathrm{Co}-\mathrm{C}}$ also corresponds to the $501 \mathrm{~cm}^{-1}$ feature in the $\mathrm{rR}$ spectrum of natural abundance $\mathrm{Me}-\mathrm{Co}^{3+} \mathrm{CFeSP}$ (Figure 5B) we have isotopically labeled the enzyme-bound cofactor. Indeed, selective ${ }^{13} \mathrm{C}$ labeling of the methyl group downshifts the $v_{\mathrm{Co}-\mathrm{C}}$ mode by $10 \mathrm{~cm}^{-}$to $491 \mathrm{~cm}^{-1}$ (Figure $5 \mathrm{C}$ ); it shifts further, to $480 \mathrm{~cm}^{-1}$, when the methyl group is fully deuterated (Figure 5D). As the frequency of the $v_{\mathrm{Co}-\mathrm{C}}$ mode and the magnitudes of the isotope shifts for $\mathrm{Me}-\mathrm{Co}^{3+} \mathrm{CFeSP}$ are identical to those observed for base-off $\mathrm{MeCbl},{ }^{64}$ it can be concluded that the $\mathrm{Co}-\mathrm{C}$ bond strength is unaffected by binding of the cofactor to the protein. Moreover, the high-energy region of the spectrum, which is dominated by corrin-based modes, is also nearly identical for base-off $\mathrm{MeCbl}$ and $\mathrm{Me}-\mathrm{Co}^{3+} \mathrm{CFeSP}$ (cf. Figure 5A, D). This finding provides an interesting contrast to the situation encountered for $\mathrm{B}_{12}$-dependent methylmalonyl-CoA mutase (MMCM), where $\mathrm{rR}$ data revealed a significant frequency upshift by $\sim 4 \mathrm{~cm}^{-1}$ of corrin ring modes upon binding of the adenosylcobalamin cofactor to the enzyme active site. ${ }^{65}$ In the case of MMCM, this perturbation of the corrin modes was interpreted as indicating that the enzyme active site forces the macrocycle to adopt a more planar conformation. 
While MCD data yield little insight into the geometric and electronic properties of diamagnetic $\left[\mathrm{Fe}_{4} \mathrm{~S}_{4}\right]^{2+}$ clusters, $\mathrm{rR}$ spectroscopy has proven to be an extremely powerful tool for identifying the set of endogenous ligands that coordinate the iron atoms of the protein-bound cluster. In the rR spectrum of Me-Co ${ }^{3+} \mathrm{CFeSP}$, a series of four peaks at $333,340,355$, and $380 \mathrm{~cm}^{-1}$ are evident that have no counterparts in the spectrum of free base-off $\mathrm{MeCbl}$ and, therefore, can be attributed to the oxidized $\left[\mathrm{Fe}_{4} \mathrm{~S}_{4}\right]^{2+}$ cluster. Based on its large intensity, the $333 \mathrm{~cm}^{-1}$ peak is assigned to the totally symmetric breathing mode of the $\mathrm{FeS}$ core; it falls within the range of frequencies (333-339 $\mathrm{cm}^{-1}$ ) reported for $\left[\mathrm{Fe}_{4} \mathrm{~S}_{4}\right]^{2+}$ clusters with all cysteinyl coordination. While only three cysteines have thus far conclusively been shown to coordinate to the $\left[\mathrm{Fe}_{4} \mathrm{~S}_{4}\right]$ cluster in $\mathrm{CFeSP}$, five Cys residues are actually present in the protein sequence of the $48 \mathrm{kDa}$ subunit, making all-cysteinyl ligation of this cluster possible. ${ }^{9}$

\section{Computational Studies. (i) Bonding Descriptions}

Previously, it has been shown that the nature of the axial ligand set has a large influence on the appearance of the Abs spectrum of $\mathrm{Co}^{3+}$ corrinoids. ${ }^{24,66-68}$ Further exploration of this spectral/structural relationship using TD-DFT calculations allowed us to correlate spectral changes observed upon $\mathrm{MeCbl}$ binding to MMCM to specific molecular distortions of the corrinoid cofactor. ${ }^{26}$ In the current study, we employed a similar approach to explore the structural origin of the spectroscopic differences between free $\mathrm{AdoCbi}^{+}$and $\mathrm{Me}-\mathrm{Co}^{3+} \mathrm{CFeSP}$ described above. As no X-ray crystal structure exists for the methylated Factor $\mathrm{III}_{\mathrm{m}}$ bound to CFeSP, a model of this cofactor (including the full complement of corrin ring substituents) was constructed using the combined quantum mechanics/molecular mechanics (QM/MM) methodology (see Computational Methods for details). Importantly, this computational scheme explicitly accounts for all electrostatic and steric effects imposed by the peripheral ring substituents on the corrin ring. The lowest energy structure, assumed to reflect the equilibrium geometry of the free $\mathrm{MeCbi}^{+}$, possessed a $\mathrm{Co}-\mathrm{OH}_{2}$ bond length of $2.250 \AA$. By varying this lower ligand bond length in fixed increments of 0.1 A between 1.8 and $3.0 \AA$ and minimizing the computed total energy with respect to the positions of all other atoms, a series of models were generated that represent points along the lower ligand dissociation coordinate. The potential energy surface associated with this axial ligand bond elongation, obtained by plotting the SCF energy of the QM region versus the $\mathrm{Co}-\mathrm{OH}_{2}$ bond length (Figure 6A), exhibits a very shallow, broad minimum and reveals that $<4 \mathrm{kcal} / \mathrm{mol}$ are required to completely dissociate the water ligand. As the $\mathrm{Co}-\mathrm{OH}_{2}$ bond is lengthened, the $\mathrm{Co}-\mathrm{O} \sigma$-bonding interaction is weakened and the bond order decreases in a monotonic fashion (Figure 6C). Concomitant with this reduction in $\mathrm{Co}-\mathrm{O}$ bond strength, all MOs that possess significant $\mathrm{Co}^{3+} 3 \mathrm{~d}_{z 2}$-orbital character are stabilized in energy due to a decrease in the $\mathrm{Co}-\mathrm{O} \sigma$-antibonding interaction induced by the strongly electron-donating methyl group trans to the water ligand (Figure 7). ${ }^{24}$ Most importantly, however, the effect of this axial $\mathrm{Co}-\mathrm{OH}_{2}$ bond elongation on the $\mathrm{Co}-\mathrm{C}$ bonding coordinate is almost negligible; the $\mathrm{Co}-\mathrm{C}$ bond length is predicted to change by no more than $0.01 \AA$ (Figure 6B) and the bond order, by $<3 \%$ over the entire range of $\mathrm{Co}-\mathrm{OH}_{2}$ bond lengths investigated (Figure 6C). A similarly weak response of the $\mathrm{Co}-\mathrm{C}$ bond properties to lower ligand distortion has been observed in previous computations for base-on $\mathrm{MeCbl}^{26}$, $64,69,70$ This lack of a significant trans influence is readily understood upon inspection of the qualitative axial ligand MO diagram in Figure 7, which reveals that even complete loss of the water ligand should not affect the $\mathrm{Co}-\mathrm{C}$ bond order (this prediction is fully consistent with the conclusion drawn from our earlier work on $\mathrm{Me}-\mathrm{Co}^{3+}$ corrinoids possessing different lower ligands). ${ }^{24}$ Collectively, these results indicate that the nature of the $\mathrm{Co}-\mathrm{C}$ bond is insignificantly affected by changes in the trans axial ligand position and/or identity; thus, protein induced distortions at the lower face of the corrinoid are not expected to affect the strength of the $\mathrm{Co}-\mathrm{C}$ bond to any significant degree. 


\section{Spectro/Structural Correlation}

The effects of axial ligand bond deformations on the appearance of the electronic Abs spectrum of corrinoids can be explored computationally using the TD-DFT method as demonstrated recently by Brooks et al. ${ }^{26}$ TD-DFT computed Abs spectra for selected $\mathrm{MeCbi}^{+}$models that represent points along the lower ligand dissociation coordinate (Figure 6) are shown in Figure 8 . These spectra reveal that the position of the intense $\alpha$-band that dominates the visible region of the computed (and experimental) $\mathrm{MeCbi}^{+} \mathrm{Abs}$ spectrum is particularly sensitive to variations in the $\mathrm{Co}-\mathrm{OH}_{2}$ bond length. This sensitivity reflects the small but significant $\mathrm{Co} 3 \mathrm{~d}_{z 2}$-orbital character $(\sim 5 \%)$ carried by the HOMO that serves as the donor MO in the transition responsible for the $\alpha$-band (Figure 7). As the lower ligand bond length increases, the consequent weakening of the $\mathrm{Co}-\mathrm{O} \sigma$-antibonding interaction leads to stabilization of the HOMO and, thus, to an increase in the energy of the $\alpha$-band transition. Our TD-DFT results predict that the $\alpha$-band blue-shifts by $\sim 20 \mathrm{~cm}^{-1} / \mathrm{pm}$ as the $\mathrm{Co}-\mathrm{OH}_{2}$ bond is lengthened from its equilibrium position toward the dissociation limit (Table S8). ${ }^{71}$ Therefore, a $0.2 \AA$ increase in the $\mathrm{Co}-\mathrm{OH}_{2}$ bond length is sufficient to rationalize the $390 \mathrm{~cm}^{-1}$ blue-shift of the $\alpha$-band observed experimentally when comparing $\mathrm{AdoCbi}^{+}$to $\mathrm{Me}-\mathrm{Co}^{3+} \mathrm{CFeSP}$ (Figure 4A). Note that for a $\mathrm{Co}-\mathrm{OH}_{2}$ bond length change of this magnitude, the positions of the higher-energy Abs features are predicted to be virtually unaffected (Figure 8), consistent with our $\mathrm{CD}$ data of $\mathrm{AdoCbi}^{+}$and $\mathrm{Me}-$ $\mathrm{Co}^{3+} \mathrm{CFeSP}$ (Figure 4B). Importantly, elongation of the $\mathrm{Co}-\mathrm{OH}_{2}$ bond beyond $2.5 \AA$ or complete removal of the lower ligand results in changes in the predicted Abs spectrum that are too dramatic to be consistent with our experimental data. Therefore, it is reasonable to conclude that, like free $\mathrm{MeCbi}^{+}$and $\mathrm{AdoCbi}^{+}$, the $\mathrm{Me}-\mathrm{Co}^{3+} \mathrm{CFeSP}$ maintains a water ligand in the lower axial position; however the $\mathrm{Co}^{3+}-\mathrm{O}$ bond length is slightly lengthened for the protein-bound cofactor. $^{72}$

\section{Discussion}

The biogenesis of acetyl-CoA is an essential step in the Wood-Ljungdahl pathway for energy generation and/or carbon fixation by a variety of anaerobic microbes. While it has been known for some time that the methyl group required for this reaction is supplied to the active site of acetyl-CoA synthase (ACS) by a corrinoid-iron-sulfur protein (CFeSP), the nature of the coordination environment of the corrinoid cofactor in the physiologically relevant $\mathrm{Co}^{3+}$ and $\mathrm{Co}^{2+}$ oxidation states has remained the subject of some debate. This is an important issue because axial ligation can markedly influence the mechanism and the rate of methyl transfer and the efficiency and rate of reduction of inactive $\mathrm{Co}^{2+}$ to the active $\mathrm{Co}^{1+}$ state. ${ }^{19-23,73,74}$ To better understand the nature of axial coordination, we have compared the MCD, EPR, and resonance Raman spectra of the free corrinoid center with those of CFeSP-bound Factor $\mathrm{III}_{\mathrm{m}}$. Using our earlier spectroscopic characterizations of free $\mathrm{AdoCbi}^{+}$and $\mathrm{Co}^{2+} \mathrm{Cbi}^{+}$as the basis for a comparison, ${ }^{24,25}$ we have evaluated spectral differences observed between these free corrinoids and the methylated and reduced forms of the CFeSP-bound 5methoxybenzimidazolyl cobamide cofactor $\left(\right.$ Factor $\mathrm{III}_{\mathrm{m}}$ ) in terms of enzyme-induced perturbations of the lower axial ligand. The implications of our findings with respect to the mechanisms of $\mathrm{Co}^{2+} \mathrm{CFeSP}$ reactivation and methyl group transfer from $\mathrm{Me}-\mathrm{Co}^{3+} \mathrm{CFeSP}$ to ACS are discussed below.

\section{Reactivation of $\mathrm{Co}^{2+} \mathrm{CFeSP}$}

Based on the close resemblance of the corresponding MCD spectra, we conclude that the corrinoid cofactor present in as-isolated, oxidatively inactivated $\mathrm{Co}^{2+} \mathrm{CFeSP}$ experiences a nearly identical coordination environment as free $\mathrm{Co}^{2+} \mathrm{Cbi}^{+}$(Figure 2); namely, it is bound in the base-off conformation where the lower methoxybenzimidazolyl (MBI) moiety is displaced and a water molecule or a protein-derived oxygen-donor ligand binds to the cobalt center. Further insight into the axial ligation of Factor $\mathrm{III}_{\mathrm{m}}$ in $\mathrm{CFeSP}$ is provided by the EPR spectrum 
of $\mathrm{Co}^{2+} \mathrm{CFeSP}$ obtained in isotopically labeled water (Figure 3 ). The dramatic loss of intensity in the $g_{\|}$region of this spectrum relative to the spectrum in natural abundance water is readily attributed to ${ }^{17} \mathrm{O}$-induced hyperfine broadening and conclusively proves that $\mathrm{H}_{2} \mathrm{O}$ coordinates to the metal center in one of the open axial positions.

Originally, the appearance of a modestly intense pre-edge $(1 \mathrm{~s} \rightarrow 3 \mathrm{~d})$ feature in X-ray Abs spectra of $\mathrm{Co}^{2+} \mathrm{CFeSP}$ had been interpreted as indicating that the cobalt ion in the enzyme-bound cofactor occupies a near-centrosymmetric site, consistent with an approximately fourcoordinate square-planar ligand environment. ${ }^{16,17}$ Yet, on the basis of our recent computational studies on a series of $\mathrm{Co}^{2+} \mathrm{Cbi}^{+}$models with varying $\mathrm{Co}-\mathrm{OH}_{2}$ bond lengths, lower axial ligand dissociation should drastically alter the energies of the Co 3d-based ligand field (LF) transitions and the EPR parameters (e.g., $g$-values and ${ }^{59} \mathrm{Co}$ hyperfine coupling constants). ${ }^{27}$ However, no such dramatic alterations are actually observed in the case of asisolated $\mathrm{Co}^{2+} \mathrm{CFeSP}$, thus arguing against the presence of a four-coordinate $\mathrm{Co}^{2+}$ corrinoid species in this enzyme. Further evidence against this unusual $\mathrm{Co}^{2+}$ ligand environment proposed for $\mathrm{Co}^{2+} \mathrm{CFeSP}$ comes from our recent studies of $\mathrm{Co}^{2+} \mathrm{Cbl}$ bound to the human methionine adenosyltransferase (ATR), which permitted the first spectroscopic characterization of a four-coordinate $\mathrm{Co}^{2+}$ corrinoid species. ${ }^{75}$ As predicted by our computations, the spectral properties of this species were found to be strikingly different from those of either $\mathrm{Co}^{2+} \mathrm{Cbi}^{+}$or $\mathrm{Co}^{2+} \mathrm{CFeSP}$.

ATRs involved in adenosylcobalamin biosynthesis and corrinoid-dependent methyltransferases (e.g., methionine synthase (MetH) and the CFeSP) are thought to employ a common mechanism for $\mathrm{Co}-\mathrm{C}$ bond formation wherein the metal center of the corrinoid substrate is fully reduced to form a four-coordinate $\mathrm{Co}^{1+}$ supernucleophile that is able to attack the target carbon atom of the cosubstrate..$^{75-78}$ Owing to the low reduction potential of the $\mathrm{Co}^{2+/ 1+}$ couple, the $\mathrm{Co}^{1+}$ corrinoid intermediate is thermodynamically difficult to generate and vulnerable to oxidative inactivation back to the $\mathrm{Co}^{2+}$ state. To achieve and maintain the $\mathrm{Co}^{1+}$ oxidation state, human ATR forces the $\mathrm{Co}^{2+}$ corrinoid substrate into a four-coordinate conformation, which helps to lower the thermodynamic barrier for cobalt-ion reduction $\left(E^{\circ}=\right.$ $-490 \mathrm{mV}$ for the $\mathrm{Co}^{2+/ 1+}$ couple of $\left.\mathrm{Co}^{2+} \mathrm{Cbi}^{+}\right)$by the in vivo flavodoxin reductant $\left(E^{\circ}=-285\right.$ $\mathrm{mV}) .{ }^{74} \mathrm{CFeSP}$ instead employs a low-potential $\left[\mathrm{Fe}_{4} \mathrm{~S}_{4}\right]$ cluster $\left(E^{\circ}=-523 \mathrm{mV}\right)$ as an internal reducing system that is bound to the enzyme through four cysteine residues, ${ }^{14,15}$ as further indicated by our resonance Raman (rR) data (Figure 5). This $\left[\mathrm{Fe}_{4} \mathrm{~S}_{4}\right]^{2+/ 1+}$ potential is intermediate between that of the $\mathrm{C}$ cluster of $\mathrm{CODH}(-530 \mathrm{mV})^{79}$ and the $\mathrm{Co}^{2+/ 1+}$ couple of the bound Factor $\mathrm{III}_{\mathrm{m}}(-504 \mathrm{mV}) .{ }^{13}$ Therefore, it has been postulated that reductive activation begins with the $\mathrm{CO}$-dependent reduction of the $\mathrm{CODH} \mathrm{C}$ cluster that then transfers an electron to the $\left[\mathrm{Fe}_{4} \mathrm{~S}_{4}\right]^{2+}$ cluster of the $\mathrm{CFeSP}$, which reduces the bound Factor $\mathrm{III}_{\mathrm{m}}$ to the $\mathrm{Co}^{1+}$ state. $14,15,80$

Reduction activation is enhanced by replacement of the lower axial MBI ligand of Factor $\mathrm{III}_{\mathrm{m}}$ by a weaker water ligand when the cofactor binds to the CFeSP, generating a fivecoordinate $\mathrm{Co}^{2+}$ species that resembles $\mathrm{Co}^{2+} \mathrm{Cbi}^{+}$(see above). This ligand switch has a profound influence in the redox properties of the Co center, increasing the $\mathrm{Co}^{2+/ 1+}$ reduction potential by $\sim 120 \mathrm{mV}$ relative to that of the MBI-bound form of the cofactor found in solution $(\sim-620 \mathrm{mV}) .{ }^{13}$ Therefore, there is no thermodynamic barrier to corrinoid reduction, and CFeSP has no need to further stabilize the redox-active orbital of the $\mathrm{Co}^{2+}$ center via complete dissociation of the lower ligand, contrasting the situation encountered for ATRs.

\section{Methyl Group Transfer from Me-Co ${ }^{3+}$ CFeSP to the ACS A-Cluster}

Once the oxidatively inactivated $\mathrm{Co}^{2+} \mathrm{CFeSP}$ is reduced to the $\mathrm{Co}^{1+}$ state by the $\left[\mathrm{Fe}_{4} \mathrm{~S}_{4}\right]^{1+}$ cluster, a methyltransferase (MeTr) transfers a methyl cation from $\mathrm{CH}_{3}-\mathrm{H}_{4}$ folate to the $\mathrm{Co}^{1+}$ corrinoid intermediate. ${ }^{81}$ The product $\mathrm{Me}-\mathrm{Co}^{3+} \mathrm{CFeSP}$ then transfers this methyl group to the 
A-cluster of ACS, generating what is believed to be a Ni-CH $\mathrm{CH}_{3}$ intermediate. Kinetic experiments have shown that this transmethylation is reversible at low reduction potentials, 82 slightly favoring formation of the $\mathrm{Ni}-\mathrm{CH}_{3}$ species $\left(K_{\mathrm{eq}} \approx 2.3\right) .{ }^{83}$ This result signifies that the Ni site of the A-cluster is at least as nucleophilic as the CFeSP-bound $\mathrm{Co}^{1+}$ corrinoid species. Recent computational studies performed in our laboratory established that the proposed Ni$\mathrm{CH}_{3}$ and $\mathrm{Co}-\mathrm{CH}_{3}$ bonds are similarly strong (with $\mathrm{M}-\mathrm{CH}_{3}$ stretching force constants of 1.76 and $1.84 \mathrm{mdyn} / \AA$, respectively), an intuitive requirement for the reversibility of the methylation. ${ }^{84}$ This computational study also indicated that the conformational flexibility of the Ni site in ACS likely plays a significant role in promoting formation of the $\mathrm{Ni}-\mathrm{CH}_{3}$ bond. Thus, while the structural features of the A-cluster, which facilitate $\mathrm{Ni}-\mathrm{CH}_{3}$ bond formation, are becoming increasingly well understood, the mechanism by which CFeSP tunes the reactivity of its $\mathrm{Me}-\mathrm{Co}^{3+}$ corrinoid cofactor toward methyl-group transfer remained largely unknown. To explore possible perturbations of the methylated corrinoid's $\mathrm{Co}-\mathrm{C}$ bond induced by CFeSP, we have compared spectroscopic data of $\mathrm{Me}-\mathrm{Co}^{3+} \mathrm{CFeSP}$ to those of free base-off $\mathrm{MeCbl}$ and $\mathrm{AdoCbi}^{+}$, which are considered to be good spectroscopic models of the bound cofactor. ${ }^{64,85}$ Indeed, the corresponding sets of electronic spectra are quite similar (Figure 4), suggesting that, as in $\mathrm{Co}^{2+} \mathrm{CFeSP}$, the MBI base that serves as the lower axial ligand in the free cofactor is displaced and a water molecule is instead coordinated in the enzyme-bound form. However, a noticeable blue-shift by $390 \mathrm{~cm}^{-1}$ of the $\alpha$-band of $\mathrm{Me}-\mathrm{Co}^{3+} \mathrm{CFeSP}$ as compared to $\mathrm{AdoCbi}^{+}$suggests a slightly perturbed axial ligand bonding scheme. Conversely, $\mathrm{rR}$ spectra of the methylated enzyme indicate that the $\mathrm{Co}-\mathrm{C}$ bond properties are not altered, as the frequency of the $\mathrm{Co}-\mathrm{C}$ stretching mode is identical to that determined for base-off $\mathrm{MeCbl}$ (Figure 5). Likewise, the corrin-based modes (1400-1600 $\mathrm{cm}^{-1}$, Figure 5) have exactly the same frequencies in the free and CFeSP-bound cofactor, ruling out any significant enzymeinduced perturbation of the corrin macrocycle. Therefore, we have engaged in TD-DFT calculations to analyze the spectral differences observed between the Abs spectra of Me$\mathrm{Co}^{3+} \mathrm{CFeSP}$ and base-off $\mathrm{MeCbl}$ in terms of an elongation of the $\mathrm{Co}-\mathrm{OH}_{2}$ bond (Figure 8). These computations attribute the $390 \mathrm{~cm}^{-1}$ blue-shift of the $\alpha$-band to a $0.2 \AA$ lengthening of the lower axial ligand bond. Importantly, however, lower ligand bond deformation is predicted to have a negligible effect on the trans axial $\mathrm{Co}-\mathrm{C}$ bond (Figure 7), consistent with previous experimental studies that have shown $v_{\mathrm{Co}-\mathrm{C}}$ to be virtually unaffected by axial ligand substitution and/or bond elongation. ${ }^{24,64,70}$

Currently, the motivation for this enzyme-induced $\mathrm{Co}-\mathrm{OH}_{2}$ bond lengthening with respect to the methyl group transfer mechanism is unclear. However, kinetic and thermodynamic studies of alkylated corrinoid species have shown that the nature of the lower ligand has a profound influence on the mode of $\mathrm{Co}-\mathrm{C}$ bond breaking. ${ }^{19,21,23}$ Specifically, the presence of an N-donor ligand in the lower axial ligand position inhibits heterolytic cleavage, whereas oxygen-donor ligands, such as water, show no such effect. This phenomenon is particularly well-exemplified by the ability of free $\mathrm{MeCbi}^{+}$to transfer its methyl group to ACS at a rate $\sim 10^{3}$ times faster than that of free MeCbl. ${ }^{85}$ Intriguingly, Me- $\mathrm{Co}^{3+} \mathrm{CFeSP}$ methylates ACS 100 -fold faster than free $\mathrm{MeCbi}^{+}$does, signaling that the protein serves to provide additional driving force for this reaction. While some of this observed rate enhancement is certainly due to favorable proteinprotein interactions between ACS and CFeSP, our spectroscopic and computational results suggest that enzyme-induced elongation of the lower axial ligand bond may also contribute. The computationally derived axial ligand bonding scheme presented in Figure 7 shows that lengthening the $\mathrm{Co}-\mathrm{OH}_{2}$ bond selectively stabilizes the formally unoccupied $\mathrm{Co} 3 \mathrm{~d}_{z 2}$ orbital so as to allow for increased mixing of this orbital with the corrin-based occupied frontier orbitals. Hence, elongation of the $\mathrm{Co}-\mathrm{OH}_{2}$ bond of the CFeSP-bound cofactor makes the cobalt center more " $\mathrm{Co}^{1+}{ }_{-}$like", a requirement for facile heterolytic $\mathrm{Co}-\mathrm{C}$ bond cleavage. Furthermore, by partially dissociating the lower water ligand, the enzyme also discourages homolytic bond cleavage given the strong preference of $\mathrm{Co}^{2+}$ corrinoids to retain an axial ligand. Moreover, the presence of a water molecule sequestered in the enzyme active site is 
expected to lessen the kinetic barrier to methylation of the $\mathrm{Co}^{1+}$ intermediate. Thus, if the protein matrix can manipulate this Co-lower ligand interaction, e.g., through hydrogen bonding or direct involvement of an active site residue, then a mechanism for tuning the reversible methyl group transfer between CFeSP and ACS is easily imagined.

\section{Supplementary Material}

Refer to Web version on PubMed Central for supplementary material.

\section{Acknowledgments}

Financial support for this work was provided by the NSF (CAREER Grant MCB-0238530) and the Sloan Research Foundation Fellowship Program to T.C.B, by NIH Grant GM39451 (to S.W.R.), and by NIH Grant 1P20RR17675 supporting the RBC Spectroscopy Core at UNL. The authors thank Dr. Frank Neese (MPI Mülheim) for supplying free copies of the ORCA software package and the WEPR spectral fitting program.

\section{References}

1. Ragsdale SW. Crit. Rev. Biochem. Mol. Biol 2004;39:165-195. [PubMed: 15596550]

2. Dobbek H, Svetlitchnyi V, Gremer L, Huber R, Meyer O. Science 2001;293:1281-1285. [PubMed: 11509720]

3. Darnault C, Volbeda A, Kim EJ, Legrand P, Vernede X, Lindahl PA, Fontecilla-Camps JC. Nature Structural Biology 2003;10:271-279.

4. Volbeda A, Fontecilla-Camps JC. J. Biol. Inorg. Chem 2004;9:525-532. [PubMed: 15221479]

5. Tan XS, Loke HK, Fitch S, Lindahl PA. J. Am. Chem. Soc 2005;127:5833-5839. [PubMed: 15839681]

6. Seravalli J, Kumar M, Ragsdale SW. Biochemistry 2002;41:1807-1819. [PubMed: 11827525]

7. Irion E, Ljungdahl LG. Biochemistry 1965;4:2780-2790. [PubMed: 5880686]

8. Ljungdahl LG, LeGall J, Lee J-P. Biochemistry 1973;12:1802-1808. [PubMed: 4699238]

9. Lu WP, Schiau I, Cunningham JR, Ragsdale SW. J. Biol. Chem 1993;268:5605-5614. [PubMed: 8449924]

10. Drennan CL, Matthews RG, Ludwig ML. Curr. Opin. Struct. Biol 1994;4:919-929. [PubMed: 7712296]

11. Although MBI is found in the native protein expressed by $M$. thermoacetica, when the CFeSP is reconstituted with cobalamin, its enzymatic properties are identical to those of the native protein (see ref $^{9}$ ).

12. Ragsdale SW, Lindahl PA, Munck E. J. Biol. Chem 1987;262:14289-14297. [PubMed: 2821001]

13. Harder SR, Lu WP, Feinberg BA, Ragsdale SW. Biochemistry 1989;28:9080-9087. [PubMed: 2605242]

14. Menon S, Ragsdale SW. J. Biol. Chem 1999;274:11513-11518. [PubMed: 10206956]

15. Menon S, Ragsdale SW. Biochemistry 1998;37:5689-5698. [PubMed: 9548955]

16. Wirt MD, Kumar M, Ragsdale SW, Chance MR. J. Am. Chem. Soc 1993;115:2146-2150.

17. Wirt MD, Kumar M, Wu JJ, Scheuring EM, Ragsdale SW, Chance MR. Biochemistry 1995;34:5269_ 5273. [PubMed: 7711048]

18. Wirt MD, Sagi I, Chen E, Frisbie SM, Lee R, Chance MR. J. Am. Chem. Soc 1991;113:5299-5304.

19. Hogenkamp HPC, Rush JE, Swenson CA. The Journal of Biological Chemistry 1965;240:3641-3644. [PubMed: 5835943]

20. Hay BP, Finke RG. J. Am. Chem. Soc 1987;109:8012-8018.

21. Kräutler B. Helv. Chim. Acta 1987;70:1268-1278.

22. Garr CD, Sirovatka JM, Finke RG. J. Am. Chem. Soc 1996;118:11142-11154.

23. Pratt, JM. Chemistry and Biochemistry of $B_{12}$. Banerjee, R., editor. Wiley; New York: 1999. p. 73-112.

24. Stich TA, Brooks AJ, Buan NR, Brunold TC. J. Am. Chem. Soc 2003;125:5897-5914. [PubMed: 12733931] 
25. Stich TA, Buan NR, Brunold TC. J. Am. Chem. Soc 2004;126:9735-9749. [PubMed: 15291577]

26. Brooks AJ, Vlasie M, Banerjee R, Brunold TC. J. Am. Chem. Soc 2004;126:8167-8180. [PubMed: 15225058]

27. Stich TA, Buan NR, Escalante-Semerena JC, Brunold TC. J. Am. Chem. Soc 2005;127:8710-8719. [PubMed: 15954777]

28. Suh S-J, Escalante-Semerena JC. J. Bacteriol 1995;177:921-925. [PubMed: 7860601]

29. Field MJ, Bash PA, Karplus M. Journal of Computational Chemistry 1990;11:700-733.

30. Personal communication with A. J. Brooks and T. C. Brunold.

31. Randaccio L, Furlan M, Geremia S, Slouf M, Srnova I, Toffoli D. Inorg. Chem 2000;39:3403-3413. [PubMed: 11196881]

32. Woo TK, Cavallo L, Ziegler T. Theor. Chem. Acc 1998;100:307-313.

33. Maseras F, Morokuma K. Journal of Computational Chemistry 1995;16:1170-1179.

34. te Velde G, Bickelhaupt FM, van Gisbergen SJA, Guerra CF, Baerends EJ, Snijders JG, Ziegler T. Journal of Computational Chemistry 2001;22:931-967.

35. Guerra CF, Snijders JG, te Velde G, Baerends EJ. Theor. Chem. Acc 1998;99:391-403.

36. ADF2004.01, SCM, Theoretical Chemistry. Vrije Universiteit; Amsterdam, The Netherlands: http://www.scm.com.

37. Vosko SH, Wilk L, Nusair M. Can. J. Phys 1980;58:1200-1211.

38. Becke AD. Physical Review A 1988;38:3098-3100. [PubMed: 9900728]

39. Perdew JP. Phys. Rev. B 1986;33:8822-8824.

40. Cornell WD, Cieplak P, Bayly CI, Gould IR, Merz KM Jr. Ferguson DM, Spellmeyer DC, Fox T, Caldwell JW, Kollman PA. J. Am. Chem. Soc 1995;117:5179-5197.

41. Swart M, Van Duijnen PT, Snijders JG. Journal of Computational Chemistry 2001;22:79-88.

42. Neese F, Solomon EI. Inorg. Chem 1999;38:1847-1865. [PubMed: 11670957]

43. Becke AD. J. Chem. Phys 1993;98:1372-1377.

44. Becke AD. J. Chem. Phys 1993;98:5648-5652.

45. Lee C, Yang W, Parr RG. Phys. Rev. B 1988;37:785-789.

46. Schäfer A, Horn H, Ahlrichs R. J. Chem. Phys 1992;97:2571-2577.

47. Schäfer A, Huber C, Ahlrichs R. J. Chem. Phys 1994;100:5829-5835.

48. Bauernschmitt R, Ahlrichs R. Chem. Phys. Lett 1996;256:454-464.

49. Casida EM, Jamorski C, Casida KC, Salahub DR. J. Chem. Phys 1998;108:4439-4449.

50. Stratmann RE, Scuseria GE, Frisch MJ. J. Chem. Phys 1998;109:8218-8224.

51. Hirata S, Head-Gordon M. Chem. Phys. Lett 1999;314:291-299.

52. Hirata S, Head-Gordon M. Chem. Phys. Lett 1999;302:375-382.

53. Neese F, Olbrich G. Chem. Phys. Lett 2002;362:170-178.

54. Lever, ABP. Inorganic Electronic Spectroscopy. Vol. 2nd ed. Elsevier; Amsterdam; New York: 1984.

55. Andruniow T, Kozlowski PM, Zgierski MZ. J. Chem. Phys 2001;115:7522-7533.

56. Craft JL, Horng YC, Ragsdale SW, Brunold TC. J. Biol. Inorg. Chem 2004;9:77-89. [PubMed: 14663648]

57. Craft JL, Horng YC, Ragsdale SW, Brunold TC. J. Am. Chem. Soc 2004;126:4068-4069. [PubMed: 15053571]

58. Van Doorslaer S, Jeschke G, Epel B, Goldfarb D, Eichel RA, Krautler B, Schweiger A. J. Am. Chem. Soc 2003;125:5915-5927. [PubMed: 12733932]

59. Giorgetti M, Ascone I, Berrettoni M, Conti P, Zamponi S, Marassi R. J. Biol. Inorg. Chem 2000;5:156166. [PubMed: 10819461]

60. Stephens PJ, Thomson AJ, Dunn JBR, Keiderling TA, Rawlings J, Rao KK, Hall DO. Biochemistry 1978;17:4770-4778. [PubMed: 728385]

61. Johnson, MK.; Robinson, AE.; Thomson, AJ. Iron-Sulfur Proteins. Spiro, TG., editor. WileyInterscience; New York: 1982. p. 367-406.

62. Bayston JH, Looney FD, Pilbrow JR, Winfield ME. Biochemistry 1970;9:2164-2172. [PubMed: 4315132] 
63. Pilbrow, JR. B 12 . Dolphin, D., editor. Wiley; New York: 1982. p. 431-462.

64. Dong SL, Padmakumar R, Banerjee R, Spiro TG. J. Am. Chem. Soc 1996;118:9182-9183.

65. Dong SL, Padmakumar R, Maiti N, Banerjee R, Spiro TG. J. Am. Chem. Soc 1998;120:9947-9948.

66. Schrauzer GN, Lee L-P. J. Am. Chem. Soc 1968;90:6541-6543. [PubMed: 4300777]

67. Schneider, Z.; Stroinski, A. Comprehensive B B $_{12}$ : Chemistry, Biochemistry, Nutrition, Ecology and Medicine. De Gruyter; New York: 1987.

68. Pratt, JM. Chemistry and Biochemistry of $\mathrm{B}_{12}$. Banerjee, R., editor. Wiley; New York: 1999. p. 113-164.

69. Kozlowski PM, Zgierski MZ. J. Phys. Chem. B 2004;108:14163-14170.

70. Dong SL, Padmakumar R, Banerjee R, Spiro TG. Inorg. Chim. Acta 1998;270:392-398.

71. While no experimental data are currently available to verify our TD-DFT based hypothesis that a lengthening of the $\mathrm{Co}-\mathrm{OH}_{2}$ bond in $\mathrm{MeCbi}^{+}$would give rise to a blue-shift of the $\alpha$-band, we note that this prediction is consistent with the fact that substitution of the DMB in MeCbl (a moderately strong $\sigma$-donor) by a water ligand (a weak $\sigma$-donor) to generate $\mathrm{MeCbi}^{+}$gives rise to a substantial shift of the $\alpha$-band in the Abs spectrum from $\sim 18950$ to $21800 \mathrm{~cm}^{-1}$ (see ref ${ }^{24}$ ). Hence, a further decrease in the $\sigma$-donor strength of the lower axial ligand, e.g., via lengthening of the $\mathrm{Co}-\mathrm{OH}_{2}$ bond, should give rise to an additional blue-shift of the $\alpha$-band, consistent with our TD-DFT results.

72. (On the basis of a pressure-dependence study, van Eldik, Pratt, and co-workers (Hamza MSA, van Eldik R, Harper PLS, Pratt JM, Betterton EA. Eur. J. Inorg. Chem 2002:2580-2583.) proposed that the interconversion between the yellow (high-temperature) and red (low-temperature) forms of $\mathrm{MeCbi}^{+}$involves the coordination/release of a water molecule. However, their data do not provide any direct evidence that this putative additional water molecule in the red form occupies the lower axial position and that this position is vacant in the yellow form (which, spectroscopically, is indistinguishable from $\mathrm{AdoCbi}^{+}$). In fact, on the basis of our TD-DFT based spectro/structural correlations (Figure 8), the close resemblance of the Abs spectra of the yellow and red forms of $\mathrm{MeCbi}^{+}$, in particular the lack of any notable differences in the near-UV region, would suggest that the ligand environments of the $\mathrm{Co}^{3+}$ center in these two forms are actually quite similar.

73. Lexa D, Saveant J-M. J. Am. Chem. Soc 1980;102:4851-4852.

74. Lexa D, Saveant JM. Acc. Chem. Res 1983;16:235-243.

75. Stich TA, Yamanishi M, Banerjee R, Brunold TC. J. Am. Chem. Soc 2005;127:7660-7661. [PubMed: 15913339]

76. Banerjee RV, Harder SR, Ragsdale SW, Matthews RG. Biochemistry 1990;29:1129-1135. [PubMed: 2157485]

77. Fonseca MV, Escalante-Semerena JC. J. Biol. Chem 2001;276:32101-32108. [PubMed: 11408479]

78. Leal NA, Olteanu H, Banerjee R, Bobik TA. J. Biol. Chem 2004;279:47536-47542. [PubMed: 15347655]

79. Lindahl PA, Munck E, Ragsdale SW. J. Biol. Chem 1990;265:3873-3879. [PubMed: 2154491]

80. Tan XS, Sewell C, Yang QW, Lindahl PA. J. Am. Chem. Soc 2003;125:318-319. [PubMed: 12517128]

81. Doukov T, Seravalli J, Stezowski JJ, Ragsdale SV. Structure 2000;8:817-830. [PubMed: 10997901]

82. Lu WP, Harder SR, Ragsdale SW. J. Biol. Chem 1990;265:3124-3133. [PubMed: 2303444]

83. Tan XS, Sewell C, Lindahl PA. J. Am. Chem. Soc 2002;124:6277-6284. [PubMed: 12033855]

84. Schenker R, Mock MT, Kleber-Emmons MT, Riordan CG, Brunold TC. Inorg. Chem 2005;44:36053617. [PubMed: 15877445]

85. Seravalli J, Brown KL, Ragsdale SW. J. Am. Chem. Soc 2001;123:1786-1787. [PubMed: 11456791] 


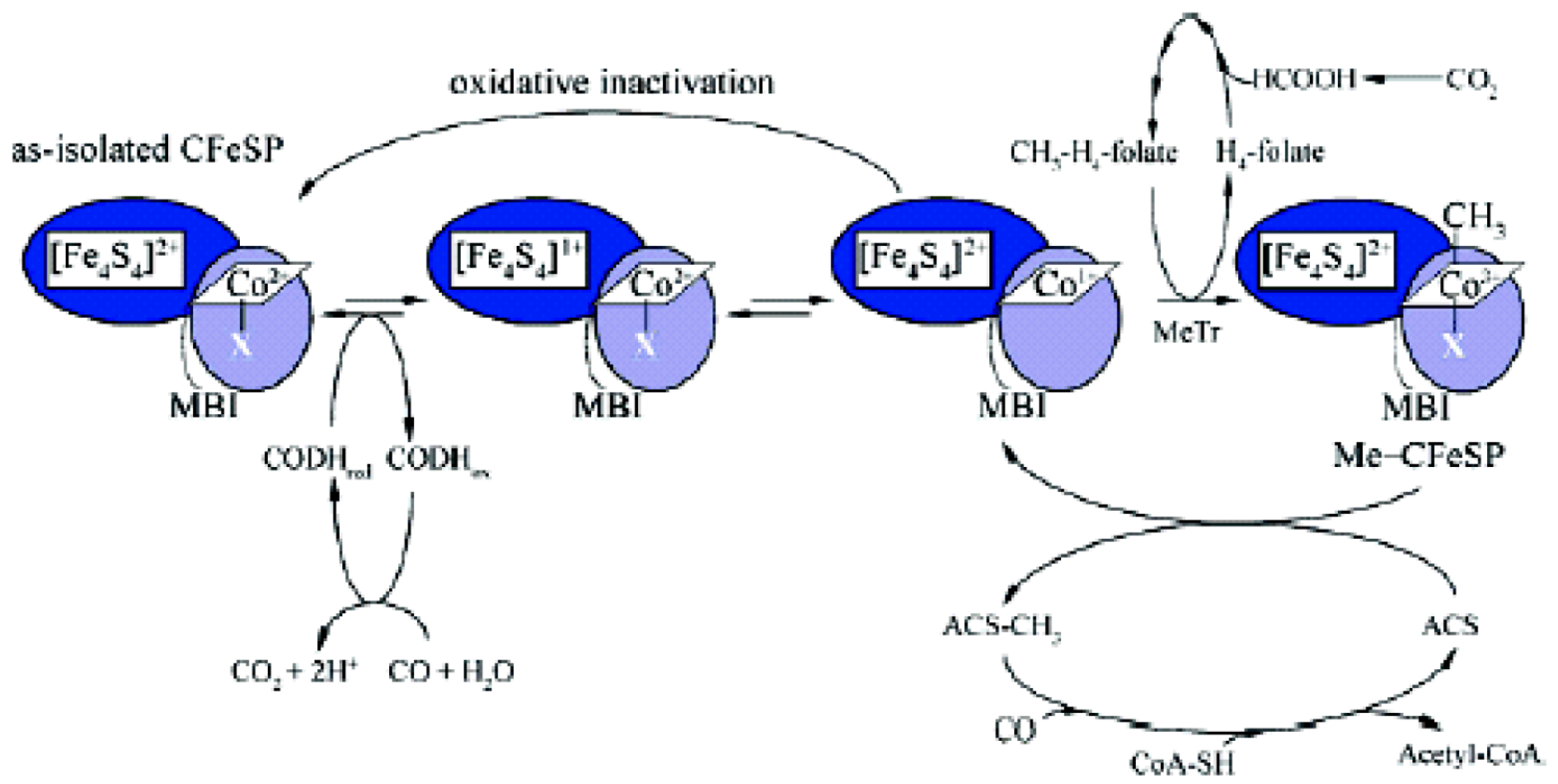

Scheme 1.

Adapted from ref ${ }^{12}$. 


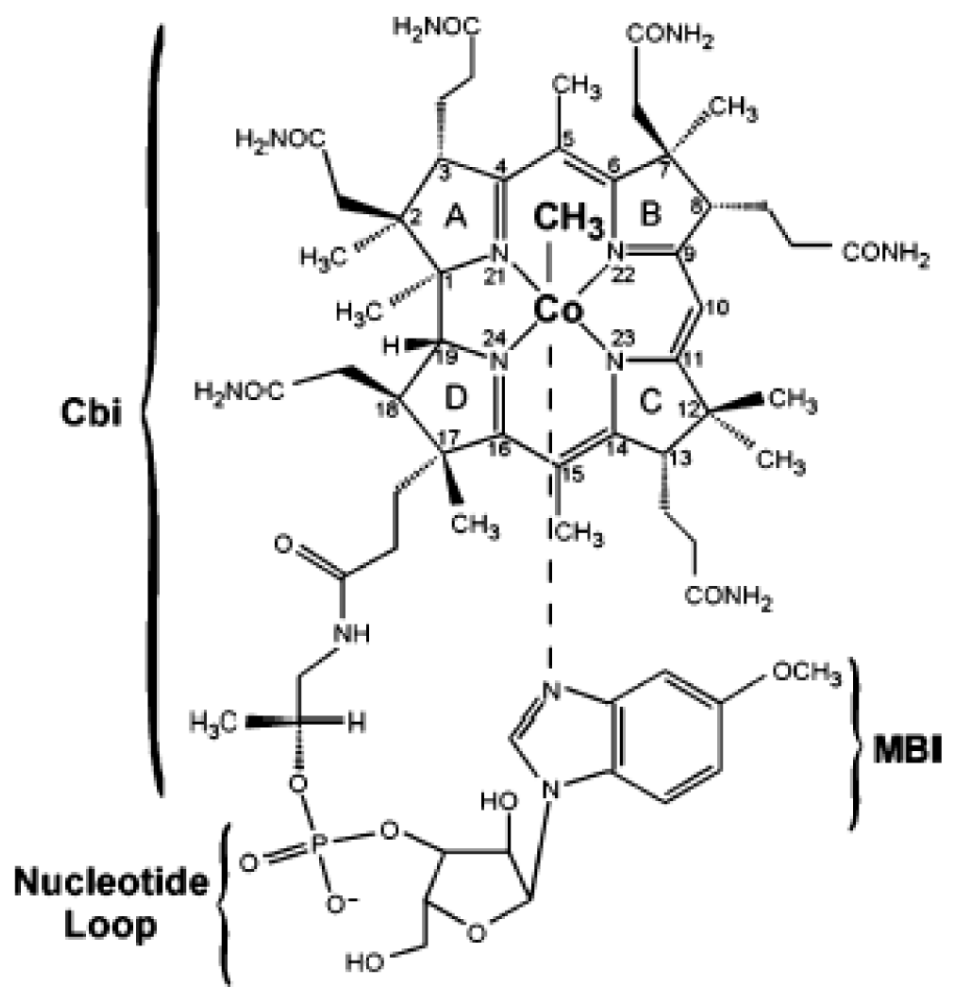

Figure 1.

Chemical structure and numbering scheme for the CFeSP cofactor, Factor $\mathrm{III}_{\mathrm{m}}$ (methyl$\mathrm{Co}^{3+}-5$ 'methoxybenzimidazolyl cobamide). 


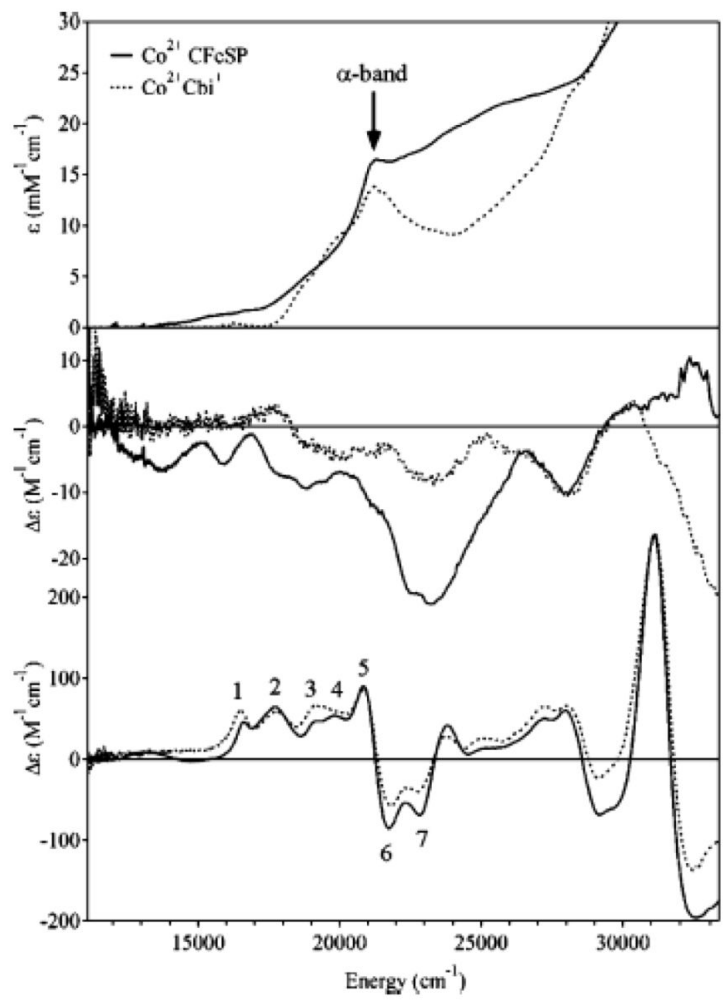

Figure 2.

Comparison of $4.5 \mathrm{~K}$ Abs (top), $\mathrm{CD}$ (middle), and $7 \mathrm{~T} \mathrm{MCD} \mathrm{(bottom)} \mathrm{spectra} \mathrm{of} \mathrm{as-isolated}$ $\mathrm{Co}^{2+} \mathrm{CFeSP}$ (solid lines) and $\mathrm{Co}^{2+} \mathrm{Cbi}^{+}$(dotted lines). 


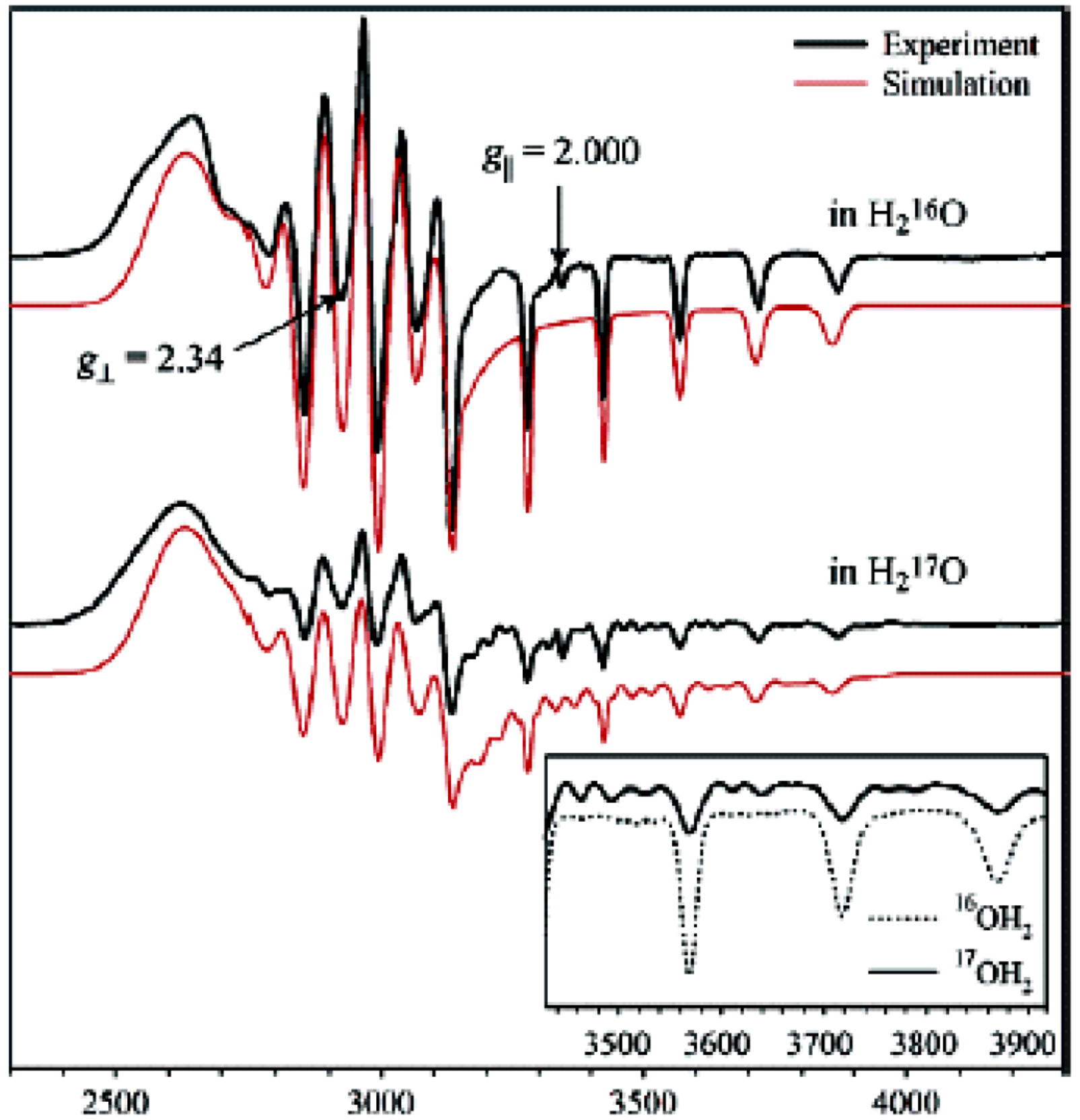

Field (Gauss)

Figure 3.

Experimental (thick black lines) and simulated (thin red lines) X-band EPR spectra of $\mathrm{Co}^{2+} \mathrm{CFeSP}$ resuspended in natural abundance $\mathrm{H}_{2} \mathrm{O}$ (top) and $\mathrm{H}_{2} 17 \mathrm{O}$ (bottom). Inset: Exploded view reveals additional features in the high-field region of the EPR spectrum of $\mathrm{Co}^{2+} \mathrm{CFeSP}$ resuspended in $\mathrm{H}_{2} 17 \mathrm{O}$ (solid line) compared to that resuspended in n.a. $\mathrm{H}_{2} \mathrm{O}$ (dotted line). EPR spectra were recorded at $100 \mathrm{~K}$ using $9.39 \mathrm{GHz}$ microwave frequency, 16 $\mathrm{mW}$ microwave power, $10.4 \mathrm{G}$ modulation amplitude, and $100 \mathrm{kHz}$ modulation frequency. Relevant EPR parameters and complete simulation input files are given in Table 2 and the Supporting Information, respectively. 


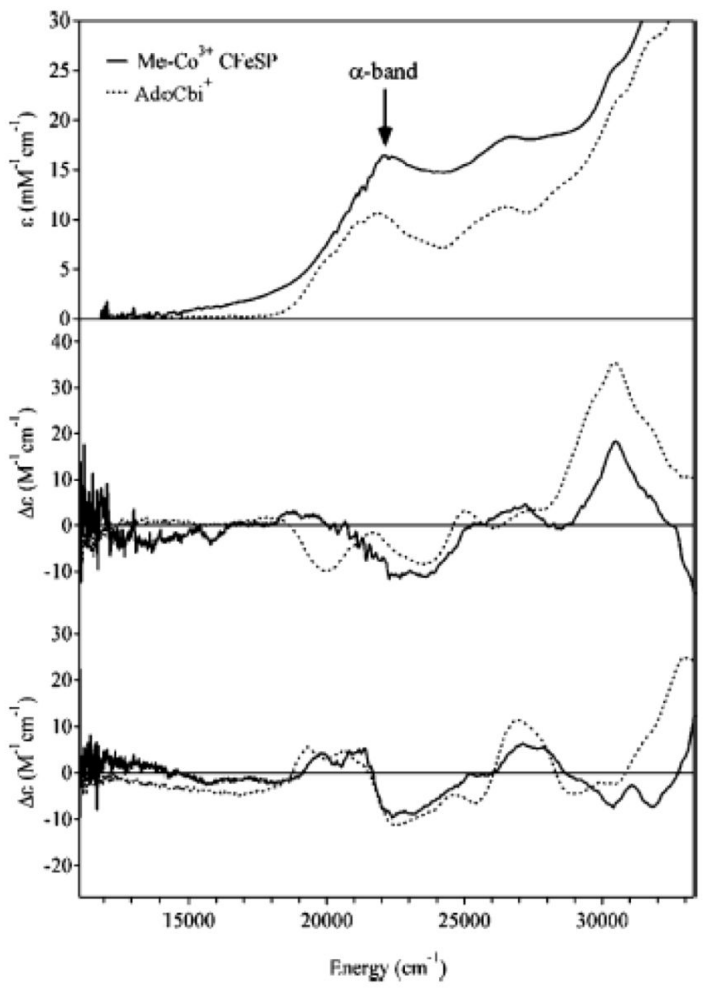

Figure 4.

Comparison of 4.5 K Abs (top), 4.5 K CD (middle), and $7 \mathrm{~T} 100 \mathrm{~K}$ MCD (bottom) spectra of methylated CFeSP (solid lines) and AdoCbi ${ }^{+}$(dotted lines) 

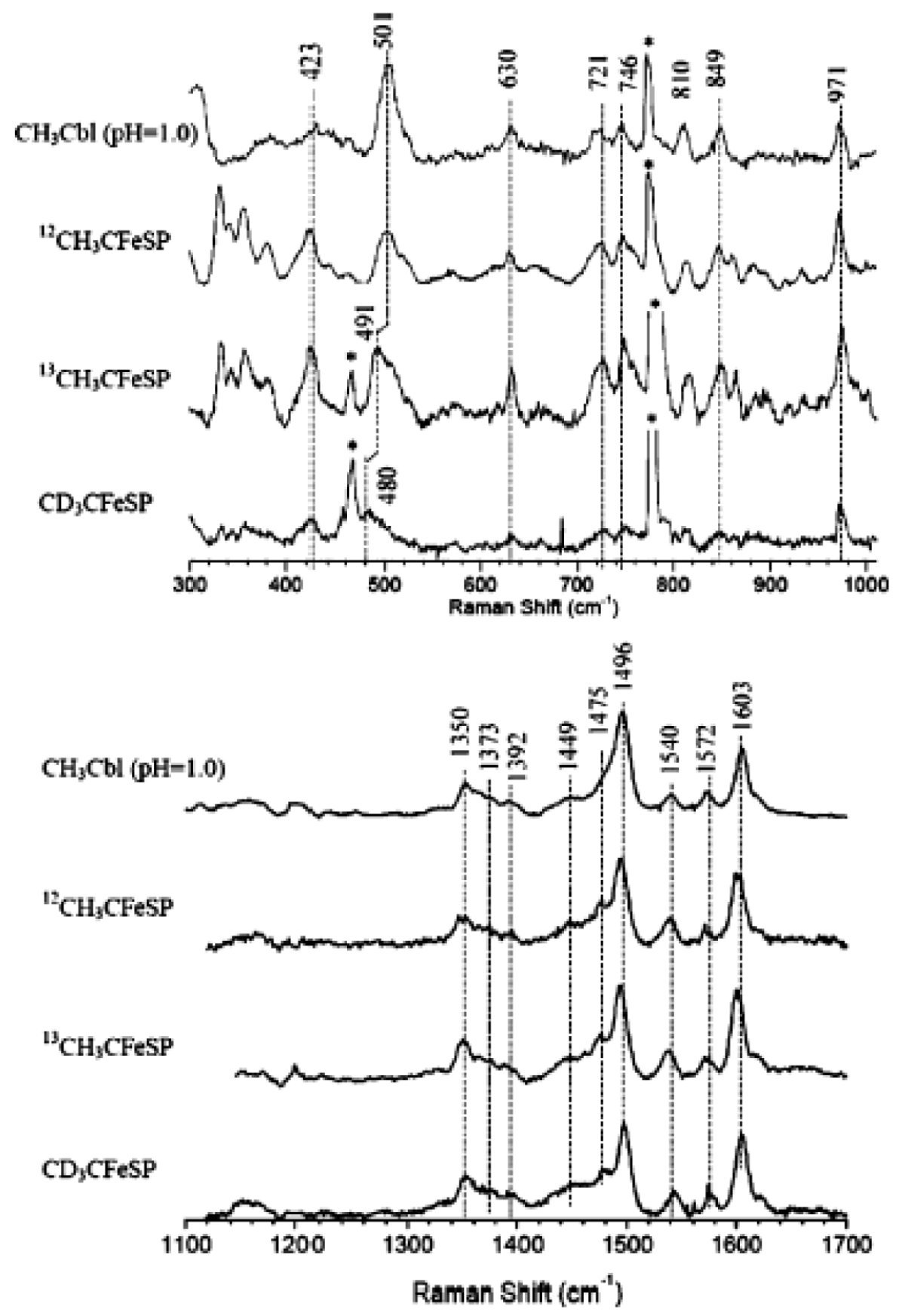

Figure 5.

Low-frequency (top panel) and high-frequency (bottom panel) regions of the resonance Raman spectra obtained for MeCbl at pH 1.0 (A), ${ }^{12} \mathrm{CH}_{3}-\mathrm{CFeSP}(\mathrm{B}),{ }^{13} \mathrm{CH}_{3}-\mathrm{CFeSP}(\mathrm{C})$, and $\mathrm{CD}_{3}-$ $\mathrm{CFeSP}$ (D). All data were collected at $77 \mathrm{~K}$ with $441.6 \mathrm{~nm}$ laser excitation 
A.
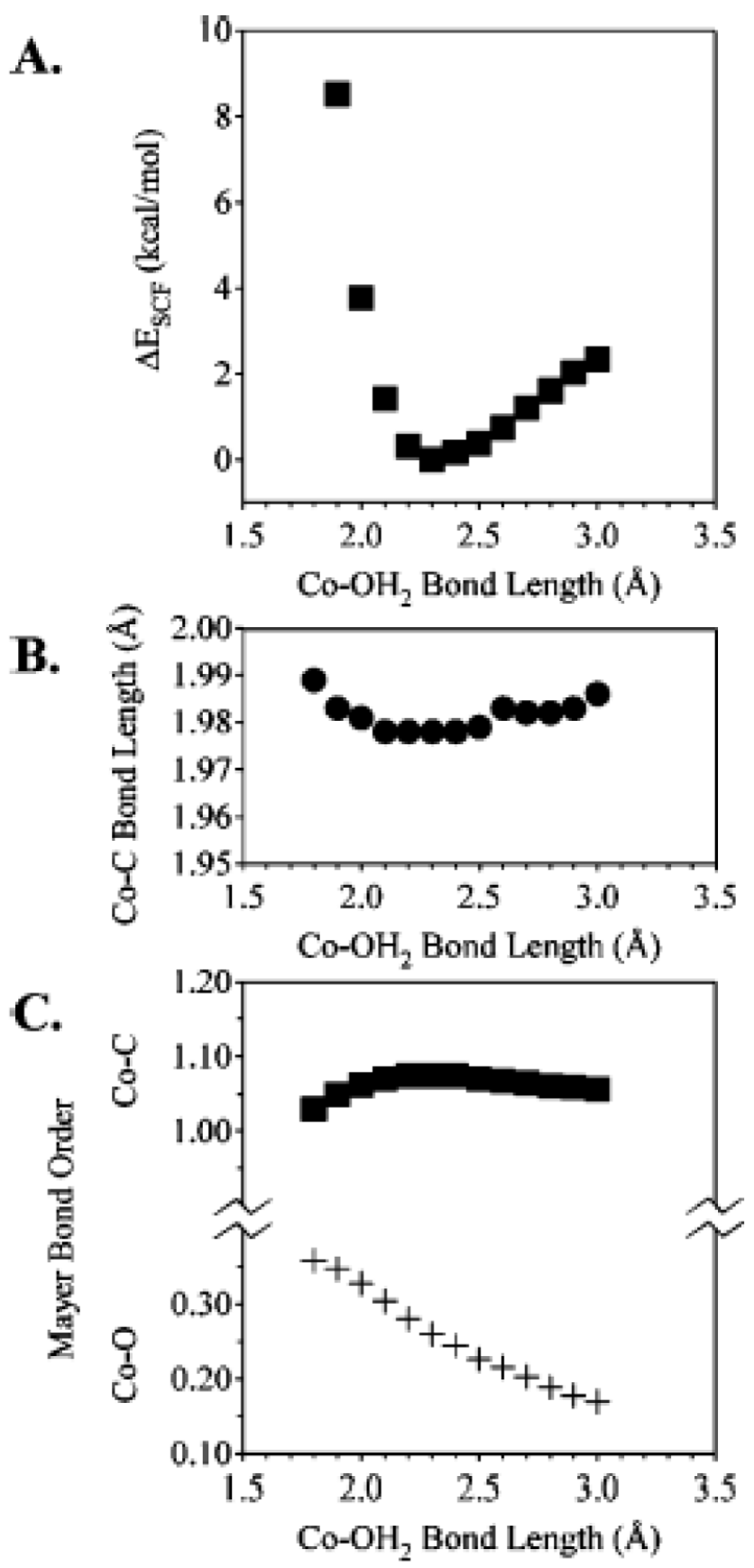

Figure 6.

Calculated potential energy surfaces (A), $\mathrm{Co}-\mathrm{CH}_{3}$ bond length (B), and nature of axial ligand bonding $(\mathrm{C})$ as a function of $\mathrm{Co}-\mathrm{OH}_{2}$ bond length for a series of QM/MM optimized $\mathrm{MeCbi}^{+}$models. 


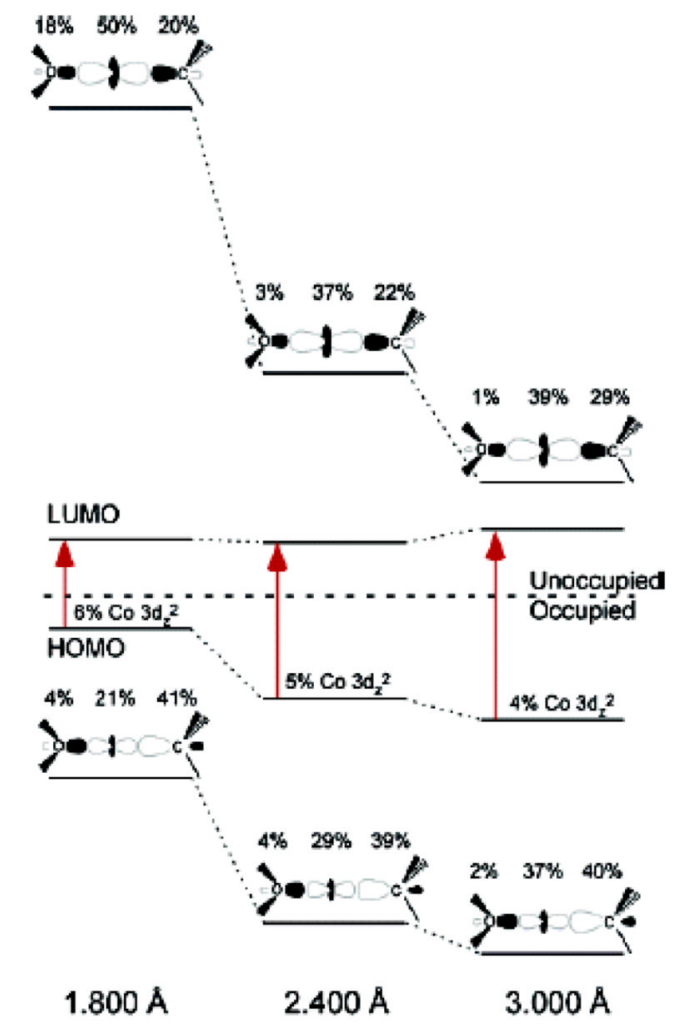

Figure 7.

Calculated MO diagram detailing the relative energies and compositions of the HOMO, LUMO, and orbitals involved in the dominant axial ligand bonding interactions for selected QM/MM optimized $\mathrm{MeCbi}^{+}$models with lower axial ligand $\mathrm{Co}-\mathrm{OH}_{2}$ bond lengths of $1.8 \AA$. (left), $2.4 \AA$ (center), and $3.0 \AA$ (right). The percent contributions from the Co $3 \mathrm{~d}_{z} 2$, water $2 \mathrm{p}_{z}$, and methyl $2 \mathrm{p}_{z}$ orbitals are noted. Red arrows indicate the donor and acceptor MOs involved in the $\alpha$-band transition predicted for each model using TD-DFT. 


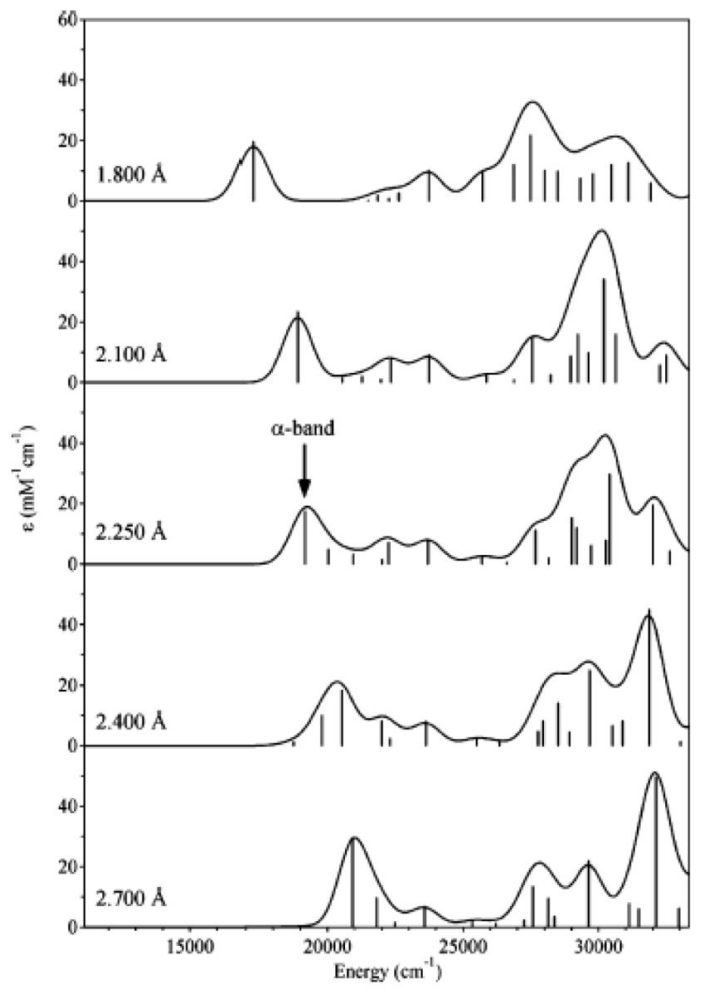

Figure 8.

TD-DFT/B3LYP predicted Abs spectra for QM/MM optimized $\mathrm{MeCbi}^{+}$models with lower axial ligand bond lengths fixed at values ranging from 1.800 to $2.700 \AA$. All calculated spectra were red-shifted by $3000 \mathrm{~cm}^{-1}$ to facilitate comparison with the experimental spectroscopic data presented above. 


\section{Table 1}

Fit Parameters from a Gaussian Deconvolution of the Low-Energy Portion of the $\mathrm{Co}^{2+} \mathrm{CFeSP}_{\mathrm{MCD}} \mathrm{Spectrum}^{a}$

\begin{tabular}{|c|c|c|c|}
\hline band & energy $\left(\mathrm{cm}^{-}\right.$ & MCD $\Delta \varepsilon\left(\mathbf{M}^{-1} \mathrm{~cm}^{-1}\right)$ & $\Delta E\left(\mathrm{~cm}^{-1}\right)$ \\
\hline 1 & 16,600 & 59.6 & +150 \\
\hline 2 & 17,700 & 99.7 & +50 \\
\hline 3 & 19.100 & 53.0 & +200 \\
\hline 4 & 19,850 & 53.9 & 0 \\
\hline 5 & 21,000 & 160.4 & 0 \\
\hline 6 & 21,600 & -170.9 & 0 \\
\hline 7 & 22.900 & -114.4 & 0 \\
\hline
\end{tabular}




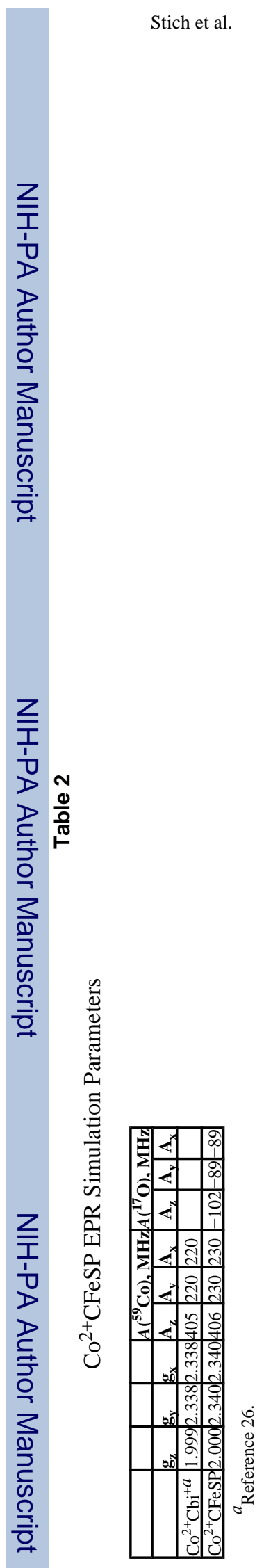

Page 25

$J$ Am Chem Soc. Author manuscript; available in PMC 2009 October 20. 